Project No. 09-788

\title{
Modeling Fission Product Sorption in Graphite Structures
}

\section{Reactor Concepts RD\&D}

Dr. Izabela Szlufarska University of Wisconsin, Madison

Brian Robinson, Federal POC Robert Bratton, Technical POC

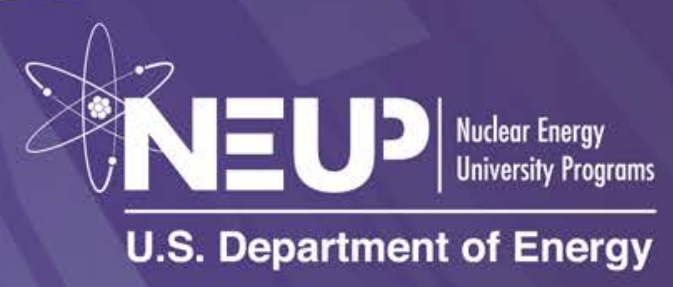




\section{Final report}

\section{MODELING FISSION PRODUCT IN GRAPHITE STRUCTURES}

Covering Period: $\quad$ October 1,2009 - September 30, 2013

Date of Report: April 5, 2013

Recipient: $\quad$ University of Wisconsin

1500 Engineering Dr

Madison, WI 53706

Contract Number: 00089350

Project Number: $\quad 09-788$
Lead PI:
Izabela Szlufarska, szlufarska@wisc.edu
Co-PIs:
Dane Morgan, Todd Allen

INL Technical Contact: Dr. Robert Bratton

\section{Project Objectives:}

The goal of this project is to determine changes in adsorption and desorption of fission products to/from nuclear grade graphite in response to a changing chemical environment. First principle calculations and thermodynamic analysis have been employed to predict fission product release on the carbon component of a nuclear reactor such as Nuclear Graphite and Fuel Rod Matrix Materials. Experimental characterization of graphite grades used in very high temperature reactors (VHTR) provided information of the structural features of carbon materials (i.e. crystallographic phases, defect structures in graphite, volume fraction of coke, amount of $\mathrm{sp} 2$ vs sp3 bonding). Experimental characterization results were used to design the numerical simulations. Simulations performed in this research were focused on studying the influence on fission product release of variables such as graphite type, plateout elements, and oxygen ingress. Within this work, sorption isotherms for isolated and coupled species were calculated, providing a better understanding of the competing release mechanisms taking place during VHTR operation. 
1 Major accomplishments and findings......................................................... 3

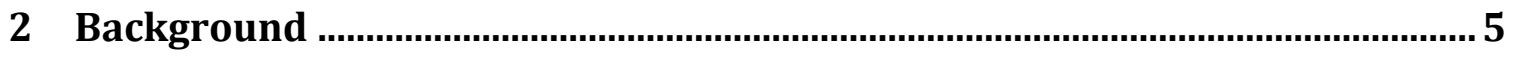

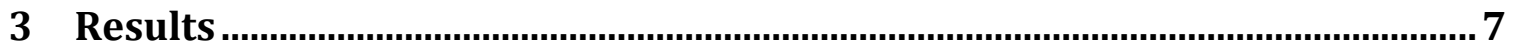

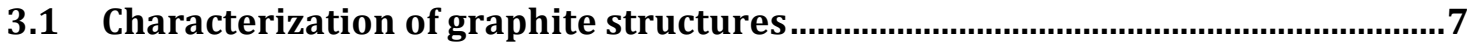

3.2 Analytical study of fission product sorption on carbon ........................................8

3.3 DFT modeling of fission product sorption on carbon ........................................... 14

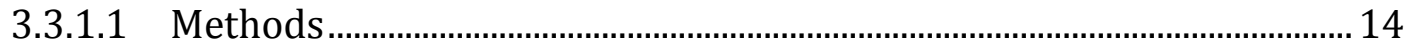

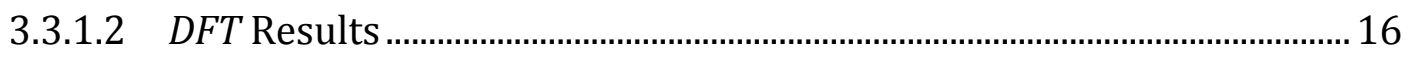

3.3.1.3 Comparison between DFT and experimental results .............................. 23

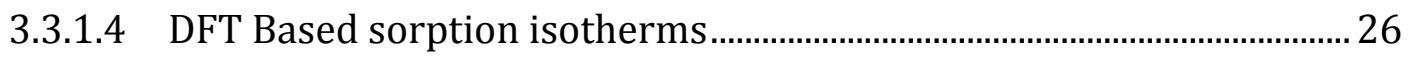

3.3.1.5 Case Study: Fission product sorption behavior during $\mathrm{O}_{2}$ ingress accident conditions on a reactor's vessel .................................................................. 29

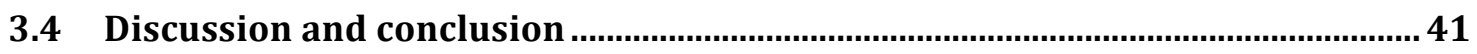

4 Publications and presentations resulting from the project........................... 44

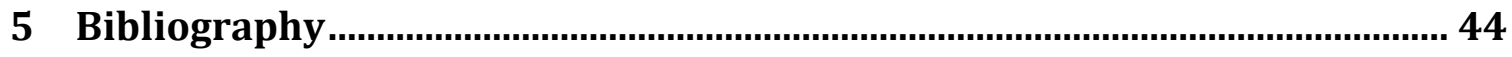




\section{Major accomplishments and findings}

- Nuclear graphite grades IGB-110 and NGB-18 were characterized. The closed porosity was found to be about $10 \%$ for both IG-110 and NBG-18, while IG-110 has a higher open porosity than NBG-18. Graphite IG-110 was found to have a higher isotropy and degree of graphitization compared to NBG-18.

- The surface area of graphites IG-110 and NBG-18 was found to be 0.4775 and $0.3601 \mathrm{~m} 2 / \mathrm{g}$, respectively. The $\mathrm{sp} 2 / \mathrm{sp} 3$ bond ratio was determined to be 9 for IG110 and 18 for NBG-18. These surface areas and apect ratios are similar to older graphite grades. Experimental results in literature for older graphite grades can therefore be used to gain qualitative knowledge of sorption behavior on graphite.

- A literature review encompassing the last 30 years of simulation and experimental work on fission product sorption on carbon was performed. This review allowed identifying the key parameters governing fission product sorption. In particular, a correlation between the degree of graphitization and the surface area of different carbon materials was found and the sorption behavior of the material characterized.

- Existing sorption isotherm models were deconstructed and analyzed. From these models, the binding energies of fission products $\mathrm{Cs}$ and $\mathrm{Sr}$ on the different carbon structures used in nuclear reactor were extracted. It was found that binding energies for $\mathrm{Cs}$ and $\mathrm{Sr}$ are stronger on amorphous carbon structures (structures primarily having sp3 bonds) than for nuclear graphite (characterized by sp3 bonds). It was also found that neutron irradiation of graphite leads to stronger binding on graphite.

- Role of carbon structure on fission product sorption: DFT calculations of Cs and Sr sorption on different carbon structures found that binding is stronger on amorphous carbon structures, than on graphitic carbon. This behavior was known from experimental results but the reasons for this behavior had remained unclear. The findings of this work allowed to confirm the role of the degree of graphitization on the sorption capacity of a carbon material and link stronger binding behavior to sp3 type of bonds.

- A trend relating strength of binding to electronic structure of fission product was found. Simulations performed for $\mathrm{Cs}$ and $\mathrm{Sr}$ sorption on different carbon structures found that the strength of the binding of an adatom a carbon surface is a function of the valence electrons of the adatom, with more valence electrons leading to stronger binding. 
- Experimental binding energies were successfully compared to DFT results. Binding energies calculated for amorphous and crystalline carbon structures were calculated using DFT calculations. These binding energies were in agreement with those calculated from experiments. These results reaffirm the role that DFT simulations on understanding carbon sorption and provide validity to the conclusions reached in this work.

- Fission product binding on graphite is governed by defects on the structure. Comparison between DFT an experimental binding energies for Cs and $\mathrm{Sr}$ on graphite showed that binding to the pristine graphite structure is too weak to explain experimental sorption and that most of the fission product sorption in graphite takes place in surfaces sites were defects are present.

- Role of neutron irradiation on fission product sorption: simulations performed for pristine graphite, graphite with vacancies and graphite with edge defects suggest that fission products bind stronger to defect structures. Comparison between DFT simulations for defect graphite and experimental irradiated graphite found similar binding behavior. These results offered and explanation and confirmed the suspected role played by irradiation on increasing the sorption of graphitic carbon. Irradiation-created defects on graphite provide sites for fission products to bind stronger.

- Sorption isotherms for fission product sorption were constructed based on DFT results and thermodynamic modeling. These isotherms can be used to predict the sorption behavior for competing binding species. Isotherms in this research were constructed for $\mathrm{Cs}$ and $\mathrm{Sr}$, but the method can readily be applied for other fission products.

- Sorption behavior in a reactor's vessel. The sorption behavior of Cs on the core of a reactor vessel was modeled. This model provides to predict fission product sorption on carbon under normal and accident conditions both under normal and accident conditions.

- Sorption under $\mathrm{O}_{2}$ ingress accident conditions. Fission product sorption on carbon was modeled for the case of $\mathrm{O}_{2}$ ingress to the reactor vessel. It was found that the carbon core of the reactor is able to contain the fission products for the case of small release such as is the case for modern TRISO particles. For the case of a high release, the carbon core surface sites will be saturated and most of the fission product will be available as a gas, increasing the chances of release to the atmosphere. 


\section{Background}

Low melting metallic fission products, such as Ag, Cs, and $\mathrm{Sr}$, can be released from intact TRISO-coated fuel particles during long-term normal operating conditions of a VHTR. These products are subsequently stored either within the graphite matrix, in which the fuel particles are embedded, or within the coolant circuit where condensable fission products can be deposited on metallic components or they can be adsorbed to the graphitic dust. During accident conditions, the inventories of fission products in graphite and in the coolant circuit can be released into the environment. It is therefore essential to quantify these inventories and thereby to determine source terms for design-basis accidents (DBA). This research is focused on predicting inventories of fission products in graphite components and more specifically on calculations of graphite sorptivity.

Two classes of accidents are particularly important for release of fission products from graphite: air and water ingress [1]. Water ingress can occur due to the failure of a heat exchanger tube, resulting in a chemical attack of water on the graphite and TRISO structure. Air ingress, which can occur due to severing of the horizontal vessel between the reactor vessel and the power conversion system vessel, results in an exposure of the graphite matrix and possibly TRISO coating layers to oxygen. The primary effect of the air and water ingress on graphite is its corrosion, which phenomenon has been extensively studied (for instance in Refs. [2-4]. It is known that $\mathrm{H}_{2} \mathrm{O}$ reacts with graphite forming $\mathrm{CO}$ gas. The remaining $\mathrm{O}$ atoms will compete with fission products for sorption sites and thus such competition may lead to an increased release of fission products stored in the graphite matrix. The effects of water and air need to be included in calculations of sorptivity of fission products on graphite.

Estimates of source terms for release of fission products from graphite are challenging because the nuclear graphite structures can be disordered and their sorptivity will be strongly dependent on specific microstructural features. For instance, sorptivity of fuel element matrix graphite A3-3 (used in the AVR pebble bed reactor) was measured to be about an order of magnitude larger as compared to a standard nuclear graphite ASR-1RG [5]. This difference was explained by the presence of $\sim 10 \%$ of ungraphitized coke binder in the matrix graphite A3-3. More graphitized microstructures, which can be obtained for example by heat treatment, will typically exhibit a reduced sorption capacity as has been shown on the example of the American type H-451 and the German types ATR-2E and ASR1 RS graphites $[6,7]$. It is therefore essential that source terms for DBA analysis account for the dependence of sorption on the specific microstructural features of graphite.

Sorptivity of graphite is also strongly dependent on the specific type of fission product, its chemical form and its concentration. For instance sorption isotherms for metallic fission products have been determined experimentally for the A3-3 graphite [7, 8]. It was shown that while $\mathrm{Sr}$ and $\mathrm{Cs}$ bind strongly to the graphite, $\mathrm{Ag}$ is sorbed only in small quantities. Consequently, sorption of Ag has been ignored in the corresponding DBA analyses [5]. The study reported in Ref. [8] also confirmed the pronounced dependence of sorptivity on a 
specific graphite structure. The authors measured Sr concentration in the A3-3 graphite and found that $\mathrm{Sr}$ inventory was bound primarily at the coked resin binder, which is a highly porous, nongraphitized material.

While the above (and similar) experimental studies have provided some very useful insights into the sorptivity of fission products on graphite, it is challenging to build predictive models and quantitative source terms based on such studies. As demonstrated in the previous paragraphs, sorptivity is strongly dependent on the microstructure. Therefore measurements carried out on one type of graphite and averaged over its microstructure cannot be easily extrapolated to another type (with different kinds of defects and their concentrations). The specific sites where different fission-product species bind, and the strength of this binding, are presently not known. Finally, models need to be developed where co-sorption of fission products is taken into account. Different fission products will compete with each other for the sorption sites and therefore the overall sorption cannot be estimated from sorption isotherms of single species. In particular, it is not known how the binding of fission products to the different sorption sites of graphite compete with oxygen at different partial pressures, and therefore how much the fission product sorptivity will change during air or water ingress accidents.

This reports addresses the above described challenges by means of DFT calculations and thermodynamic modeling combined with experimental characterization of structural properties of graphite. Results of our research activities will be presented in the following sections. The following tasks were be performed within the project:

- Task 1: Structural characterization of the VHTR graphite to determine crystallographic phases, defect structures in graphite and their distribution, volume fraction of coke, and amount of sp2 vs sp3 bonding. This information provided a guidance for DFT modeling in Task 2 and as input for sorptivity models developed in Task 3.

- Task 2: DFT calculations of binding energies were performed in order to determine stability of fission products on the different sorption sites present in nuclear graphite microstructures. Density functional theory (DFT) methods were used to calculate binding energies in vacuum and in oxidizing environments.

- Task 3: Modeling of graphite sorption isotherms was performed in order to quantify concentration of fission products in graphite. The binding energies were combined with a isotherm statistical models to predict the sorbed concentration of fission products on each type of graphite site. The model includes multiple simultaneous adsorbing species, which will allow for competitive adsorption effects between different fission product species and $\mathrm{O}_{2}$ (for modeling accident conditions). 


\section{Results}

\subsection{Characterization of graphite structures}

The physical properties of graphite are highly dependent on texture and defects introduced during forming and thermal processing. In order to ensure that our sorption calculations were carried out on relevant graphite structures, we used a number of experimental techniques to perform structural characterization of nuclear-grade graphites that are considered for Generation IV reactors. This structural characterization was performed using a combination of X-ray diffraction (XRD), transmission electron microscope (TEM), electron energy loss spectroscopy (EELS) and Raman scattering to determine crystallographic phases, defect structures in graphite, volume fraction of coke, the degree of coke graphitization, and chemical bonding in the materials to be modeled. Specifically, XRD and TEM were used to estimate volume fractions of different crystallographic phases (volume fraction of coke, fraction of graphitic vs. amorphous). A combination of Raman scattering and TEM was used to qualitatively estimate concentrations of step edges in graphite. Ratios of sp2 to sp3 bonding in selected amorphous regions were be estimated using EELS. Table 1 Presents the graphite references evaluated within this project.

\begin{tabular}{|l|l|l|l|l|l|l|}
\hline Grade & Manufacturer & $\begin{array}{l}\text { Forming } \\
\text { method }\end{array}$ & Source coke & $\begin{array}{l}\text { Grain size } \\
(\mu \mathrm{m})\end{array}$ & $\begin{array}{l}\text { Ash } \\
\text { content } \\
(\mathrm{ppm})\end{array}$ & $\begin{array}{l}\text { Density } \\
\left(\mathrm{g} / \mathrm{cm}^{3}\right)\end{array}$ \\
\hline IG-110 & Toyo Tanso & $\begin{array}{l}\text { Iso-stat. } \\
\text { molded }\end{array}$ & Petroleum & 20 & $<10$ & 1.77 \\
\hline $\begin{array}{l}\text { NBG- } \\
18\end{array}$ & SGL & $\begin{array}{l}\text { Vibra. } \\
\text { Molded }\end{array}$ & Coal & 300 & $<10$ & 1.85 \\
\hline
\end{tabular}

Table 1. Graphite references used in characterization studies.

The main findings of the graphite characterization studies are summarized are summarized as follows:

- The closed porosity was found to be about $10 \%$ for both IG-110 and NBG-18, while IG-110 has a higher open porosity than NBG-18

- The crystal size was found to be about $30 \mathrm{~nm}$ (parallel to c axis) and $60 \mathrm{~nm}$ (perpendicular to c axis) for both graphites

- IG-110 has a higher isotropy and degree of graphitization compared to NBG-18

- The appearance of the Raman D band was mainly due to edges and boundaries, and the crystal size deduced from Raman spectra is in agreement with XRD analysis

- The surface area was determined to be 0.4775 and $0.3601 \mathrm{~m} 2 / \mathrm{g}$ for IG-110 and NBG-18, and the micro-pores was found to have a slit-like shape 
- Mrozowski Cracks were found in both graphites in both nanometer and micrometer length scales using SEM and TEM. Figure 1. shows one such crack for the case of graphite NBG 18.

- $\quad$ The sp2/sp3 bond ratio was determined to be 9 for IG-110 and 18 for NBG-18.

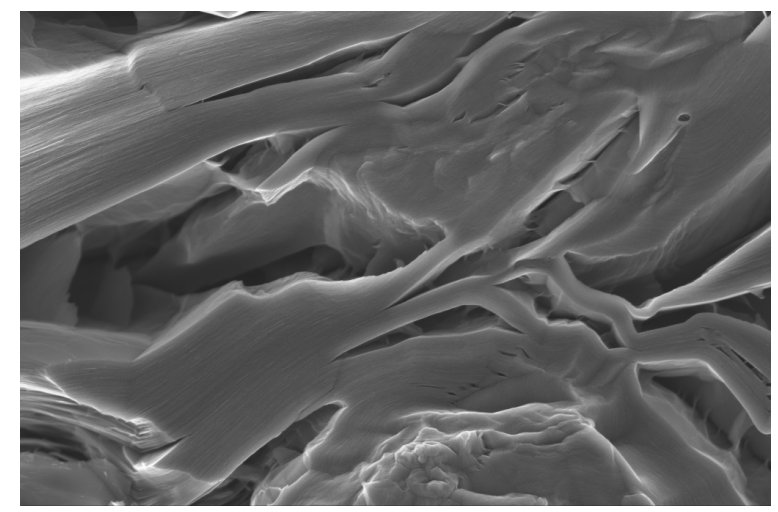

Figure 1. Mrozowski Cracks in graphite NBG-18.

\subsection{Analytical study of fission product sorption on carbon}

Along with the physical characterization of nuclear graphites, an analytical study of the behavior of fission product sorption on carbon materials was performed. This analytical study was based on a literature review of reports by national laboratories on the subject. This section introduces the sorption isotherm models used in experimental research as well as a background of the experimental activities. The analysis of previous work provided a clearer understanding of the phenomena governing fission product sorption on carbon. It also provided the guidelines to design the DFT calculations.

\section{Sorption Isotherms}

Fission product sorption in carbon structures can be characterized by using sorption isotherms that relate the partial pressure of the fission product to its concentration on the sorbent carbon structure. These types of isotherms are used to predict the amount of a fission product sorbed by a material and also provide boundary conditions (e.g., starting concentrations of fission products sorbed in different reactor components at the start of an accident) for programs predicting fission product release [9-11]. The purpose of these programs was to aid in the design of new reactors and to study release rates under accident conditions. It was of primary importance for the accuracy of these programs that correct sorption isotherms were procured $[9,12]$

In order to calculate the transport of fission products in reactors, fission product release programs relied on input data such as diffusion coefficients and release rates, which were mainly measured experimentally [13]. Obtaining accurate values of the boundary conditions was particularly challenging and fundamental to ensure accurate results. Boundary conditions obtained from one reactor did not necessarily match those obtained from another reactor. This is because the measurements to obtain boundary conditions were affected by individual plateout and liftoff at a reactor and were a function of its operating history. Therefore, in order to guarantee an accurate prediction of fission product 
release, boundary conditions had to be determined from measurements in the reactor whose behavior was to be predicted [14].

Usually, experimental data from specialized, out-of-the-reactor experiments was fitted to obtain the isotherms that were later used by the programs. These experiments were performed both on unirradiated and irradiated graphite, but with more information available for the former. Figures 2 and 3 present a compilation of experimental results and sorption isotherm models for $\mathrm{Cs}$ and $\mathrm{Sr}$ for characteristic reactor materials. Experiments presented in Figure 2 for graphite mixture H-451 and the fuel matrix material M-205 were conducted by General Atomics Company using the Knudsen cell method [6]. Figure 3 presents the results of the experiments by General Atomics and Faircloth and Crossley for graphite H-327 [15]. These experiments were performed using Knudsen cells in conjunction with mass spectrometry. Other experimental results included in the figure are Sr sorption tests on petroleum coke and from the Fort St. Vrain reactor matrix material [15].

It is observed from the figures that, as expected, for a given temperature, sorption of fission products increases with partial pressure of the fission product. By looking at the isotherms for different materials, it is observed that the matrix materials have a higher sorptivity than graphite. Matrix materials in these studies are mainly comprised of coke, either petroleumor carbon-based, which, as previously discussed, is an amorphous carbon structure known to have superior sorption capacity and high porosity. On the other hand, the only coke in graphite is found in the ungraphitized binder, leading to an inferior sorptivity. It should be noted that newer matrix materials typically use graphite powders in place of coke, which could have quite different sorption properties. However, there is no sorption isotherm data for these newer graphite powder based materials.

Experimental measurements of sorptivity found that sorption was characterized by two regions of exponential growth of concentration with partial pressure. It was postulated that this behavior could be modeled by having two regimes-one for high concentrations and one for low ones-with a transition concentration joining the two [15-18]. This two-regime model gave accurate fits to the experimental data and was incorporated into the simulation programs $[19,20]$. The standard isotherm models used to fit the empirical data were performed using Freundlich, Langmuir, and Henrian isotherms [15-18]. The different isotherm types were used depending on the concentration range of the fission product. Isotherm curves obtained using different models intersected at a transition concentration, as will be discussed below.

Freundlich isotherms were used to model sorption behavior at a high concentration. These isotherms are of the form [15]:

$\ln p=(A+B / T)+(D+E / T) \ln C$

where $p$ is the vapor pressure; $T$ is the temperature; $C$ is the concentration of sorbed species; and $A, B, D$, and $E$ are constants that are determined by a fit of the equation to the experimental data. Freundlich adsorption behavior occurs when there is a temperature dependent linear relationship of $\ln (p)$ on $\ln (C)$, while the heat of adsorption, $Q$, is linearly dependent on $\ln (C)[16,17]$ :

$Q=-R \partial \ln p / \partial(1 / T)=-R(B+E \ln C)$ 
where $R$ is the gas constant. The Freundlich isotherm model can be derived from molecular level statistical thermodynamics with the assumption that a number of adsorption sites, $N$, with energy, $X$, are distributed exponentially with the site energy [16]:

$N(X)=b \exp \left(-X / X_{m}\right)$

where $b$ and $X_{m}$ are model constants. At high concentrations of sorbed metal, when $\ln (C)$ has the value $-B / E$, Equation (2) predicts a zero heat of absorption [15]. Based on experiments, it was observed that for values of $\ln (C)$ near and greater than $-B / E$, there was a deviation from the vapor pressure predicted by the Freundlich isotherms [21]. As the concentration of sorbate decreases in the Freundlich isotherm, the heat of adsorption increases without bound. However, for the case of fission product sorption, experimental evidence showed that the heat of adsorption reached a constant limit at low concentrations [22] It was also observed that as the concentration decreased, the dependence of the vapor pressure on the concentration of sorbate was weaker than predicted by the Freundlich isotherm [22-24]. It was therefore determined that sorption of fission products at low concentrations was better described by a Henrian isotherm, which is characterized by a constant heat of adsorption and by a direct proportionality between vapor pressure and the concentration of sorbed species. However, during work on these models, attention was called to the fact that a clear existence of a Henrian behavior and the nature of transition between these two behaviors was not sufficiently well characterized. In order to take a conservative approach, it was simply assumed that below a given concentration of sorbed metal, isotherm behavior becomes that of Henry's law (Henrian isotherm) [15]:

$\ln p=(A+B / T)+(D-1+E / T) \ln C^{*}+\ln C$

This functional form is written so that at $C=C^{*}$, the value of $\ln (p)$ matches that of the value from the Freundlich isotherm in Equation (2). The model parameters $A, B, D$, and $E$ are the same in both the Henrian and Freundlich models in equations (1) and (4), respectively. The parameter, $C^{*}$, in the equation is the concentration at which the regime transition takes place. Some studies assumed a fixed value for $C^{*}$ [7], while others used a temperature dependent $C^{*}=C^{*}(T)[6,12]$. It is generally assumed that the value of the transition concentration was dependent upon the metal under consideration and upon the properties of the sorbent material. For species where no transition had been observed, it was assumed to occur at the lowest concentration at which measurements had been made [25]. The temperature dependent model assumes that the transition concentration decreases with the increase of temperature. That is, for a given material, the isotherm will change from the Henrian to the Freundlich regime at a lower concentration for a higher temperature. Table 2 presents a compilation of the constants most commonly used for the Henrian and Freundlich isotherm models for the sorption of Cs and Sr on matrix material and graphite. 


\begin{tabular}{|c|c|c|c|c|c|c|}
\hline & & \multicolumn{5}{|c|}{ Cs } \\
\hline & & $\mathbf{A}$ & B & D & $\mathbf{E}$ & $\mathrm{C}^{*}$ \\
\hline $\begin{array}{l}\text { A3-3 } \\
\text { Matrix }^{41}\end{array}$ & {$[\mathrm{~Pa}, \mathrm{~mol} / \mathrm{kg}, \mathrm{K}]$} & 3.604 & 1400 & -3.118 & 6707 & 0.00113 \\
\hline $\begin{array}{l}\text { Fuel rod } \\
\text { matrix } \\
\text { material10 }\end{array}$ & {$[\mathrm{Pa}, \mathrm{mmol} / \mathrm{kg}, \mathrm{K}]$} & 19.33 & -47290 & 1.518 & 4338 & $\begin{array}{c}\ln C^{*}=3.397- \\
6.15 \times 10^{-4} \mathrm{~T}\end{array}$ \\
\hline $\begin{array}{l}\text { Fuel rod } \\
\text { matrix } \\
\text { material } 42\end{array}$ & $\begin{array}{l}{[\mathrm{atm}, \mu \mathrm{mol} /} \\
\mathrm{g}, \mathrm{K}]\end{array}$ & 8.39 & 38300 & -0.5 & 4100 & 4.0 \\
\hline $\begin{array}{l}\text { Graphite H- } \\
451^{10}\end{array}$ & {$[\mathrm{~Pa}, \mathrm{mmol} / \mathrm{kg}, \mathrm{K}]$} & 24 & -35730 & -1.561 & 6123 & $\begin{array}{l}\ln C^{*}=2.035- \\
1.786 \times 10^{-3} \mathrm{~T}\end{array}$ \\
\hline H-32710 & {$[\mathrm{Pa}, \mathrm{mmol} / \mathrm{kg}, \mathrm{K}]$} & 19.747 & -30368 & -2.077 & 6710 & $\begin{array}{l}\ln C^{*}=0.545- \\
7.775 \times 10^{-4} \mathrm{~T}\end{array}$ \\
\hline $\mathrm{H}-327^{42}$ & {$[\mathrm{~atm}, \mu \mathrm{mol} / \mathrm{g}, \mathrm{K}]$} & 7.09 & 27600 & -0.5 & 4100 & 0.3 \\
\hline \multirow[t]{3}{*}{$P_{3}$ JHAN $^{10}$} & {$[\mathrm{~Pa}, \mathrm{mmol} / \mathrm{kg}, \mathrm{K}]$} & 27.73 & -42153 & $\begin{array}{l}-4.1 \\
\end{array}$ & 8611 & $\begin{array}{c}\ln \mathrm{C}^{*}=2.386- \\
1.86 \times 10^{-3} \mathrm{~T}\end{array}$ \\
\hline & & & & $\mathbf{S r}$ & & \\
\hline & & $\mathbf{A}$ & B & D & $\bar{E}$ & $\mathrm{C}^{*}$ \\
\hline $\begin{array}{l}\text { A3-3 } \\
\text { Matrix }\end{array}$ & {$[\mathrm{Pa}, \mathrm{mol} / \mathrm{kg}, \mathrm{K}]$} & 10.5 & -6222 & -1.591 & 6163 & 0.00015 \\
\hline $\begin{array}{l}\text { Fuel rod } \\
\text { matrix }^{32}\end{array}$ & {$[\mathrm{~atm}, \mu \mathrm{mol} / \mathrm{g}, \mathrm{K}]$} & 42.8 & $-1.49 \times 10^{5}$ & -8.52 & $\begin{array}{c}2.85 \times 10 \\
4\end{array}$ & 22.8 \\
\hline H-327 32 & {$[\mathrm{~atm}, \mu \mathrm{mol} / \mathrm{g}, \mathrm{K}]$} & 9.44 & $-4.24 \times 10^{4}$ & -0.57 & $\begin{array}{c}4.59 \times 10 \\
3\end{array}$ & 0.12 \\
\hline
\end{tabular}

Table 2. Sorption parameters for Cs and $\operatorname{Sr}[6,7,12,15]$. 


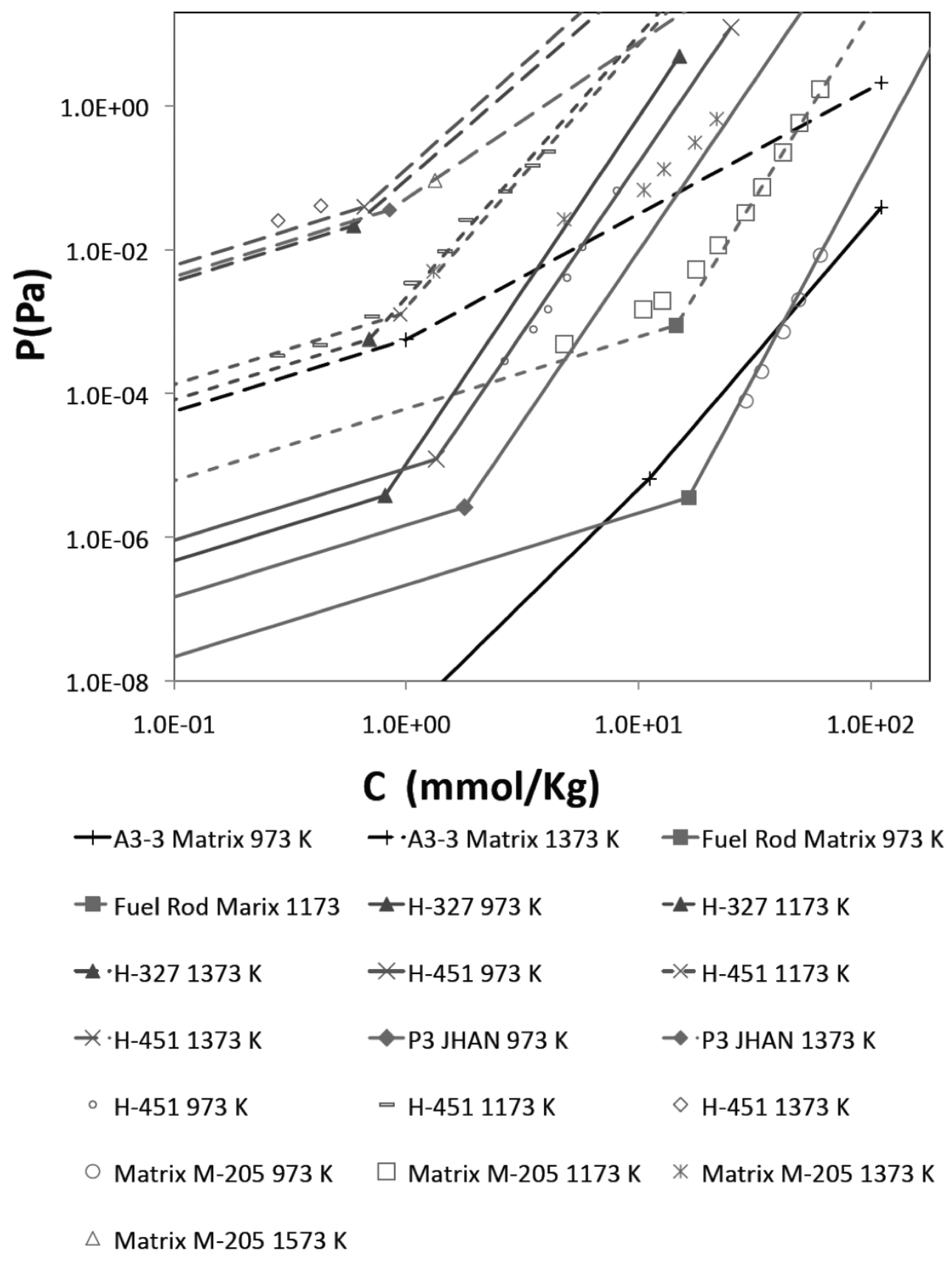

Figure 2. Experimental and isotherm model results for Cs sorption on nuclear reactor carbon materials. 


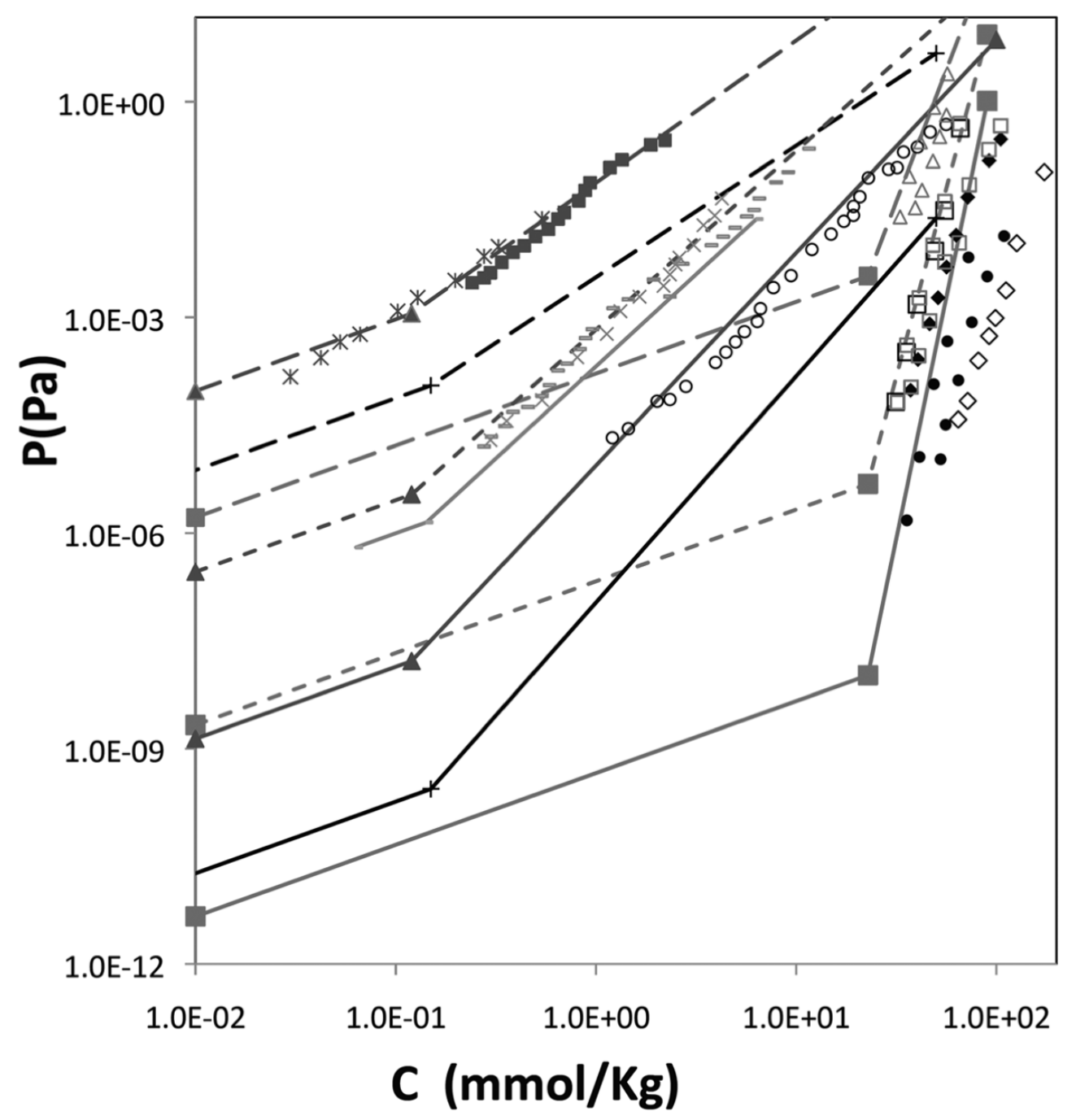

-Fuel Rod Matrix $1300 \mathrm{~K}$

$\rightarrow$ Fuel Rod Matrix $1800 \mathrm{~K}$

+•A3-3 $1800 \mathrm{~K}$

+A3-3 Matrix $1300 \mathrm{~K}$

-ـ H-327 1500

$\rightarrow \mathrm{H}-3271300 \mathrm{~K}$

- $\mathrm{H}-3271300 \mathrm{~K}$

$-\mathrm{A} \cdot \mathrm{H}-3271800$

$\times \mathrm{H}-3271500 \mathrm{~K}(2)$

- $\mathrm{H}-3271500 \mathrm{~K}(1)$

- H-327 $1800 \mathrm{~K}(1)$

$-\mathrm{H}-3271500 \mathrm{~K}(3)$

$\diamond$ Calcined pretroleum coke $2273 \mathrm{~K}$

* H-327 $1800 \mathrm{~K}(2)$

FSV Matrix (2) 1000-1530 K

- FSV Matrix (1) 1000-1530 K

- Fuel Rod Matrix T 1273

$\square$ Fuel Rod Matrix $1500 \mathrm{~K}$

$\triangle$ Fuel Rod Matrix $1800 \mathrm{~K}$

Figure 3. Experimental and isotherm model results for Cs sorption on nuclear reactor carbon materials. 
The continuous lines in Figures 2 and 3 were obtained using the isotherm models presented in Table 2. It is observed that these models offer a good fit to experimental data, but that not enough information is available for the Henrian regions to be conclusively identified. It is also observed that the transition concentration from Henrian to Freundlich isotherms is not as marked in experiments as predicted by the equations. However, the two-regime isotherm model seems to offer a reasonably good fit for the experimental results. It is also important to remark that most of this isotherm data was gathered under special environmental conditions that are not always replicated such as those found in a high temperature gas reactor. Specific areas of concern with the accuracy of these isotherm reactor models were the potential existence of some fission products in the form of chemical compounds under reactor conditions and the validity of using isotherms derived from equilibrium data to model transient conditions [26].

\subsection{DFT modeling of fission product sorption on carbon}

DFT simulations aimed at calculating the binding energies of fission products Cs and $\mathrm{Sr}$ on different carbon structures were performed as part of this research. Binding energies calculated using DFT were later compared with the ones obtained for the sorption isotherms described in the previous section. Carbon structures evaluated in this work ranged from those having only sp2 binding to those mainly having sp3 binding. Figure 4 presents a schematic representation of the structures evaluated in this research. The experimental characterization performed in this work along with the knowledge gained from the literature review indicated that graphitic materials would be characterized by sp2 binding while other materials such as Fuel Rod Matrix would be of an amorphous (combination of sp2 and sp2 binding) nature. By performing calculations in materials ranging from pure $\mathrm{sp} 2$ to pure $\mathrm{sp} 3$ the entire spectrum of possible carbon structures was sampled.

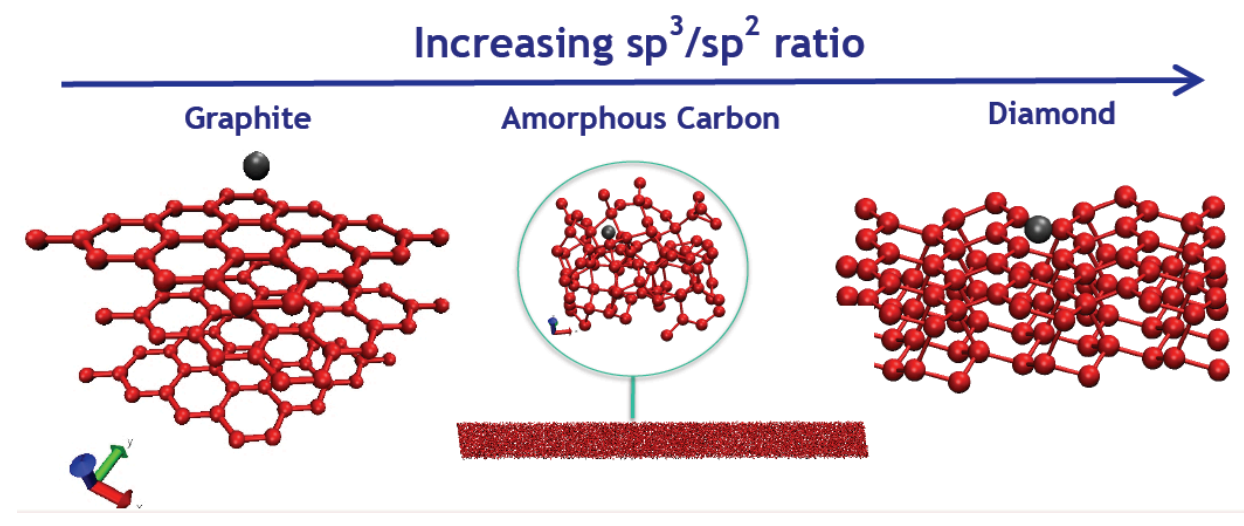

Figure 4. Atomic structures of the materials studied using DFT simulations.

\subsubsection{Methods}

Simulations in this research were performed using Density Functional Theory (DFT) as implemented in the Vienna ab initio Simulation Package (VASP)[27, 28]. The Local Density Approximation [29] was selected, with a plane wave basis set and core electrons treated within the projector augmented wave (PAW) method. Calculations are done with an energy cutoff of $600 \mathrm{eV}$. The PAW file electronic configurations used are: s2p2, 5s2 5p6 6s1 and 3s2 $3 \mathrm{p} 6$ 4s1 for C, Cs and Sr respectively. All calculations were performed with spin polarization and magnetic moments per Cs or Sr ranged from 0 to about 1 for the different structures. 
Calculations are done in reasonably large supercells to minimize interaction between sorbed atoms. However, sorbate-sorbate interactions may contribute to deviations from the dilute limit sorption energy value on the scale of $0.9 \mathrm{eV}$ and $0.5 \mathrm{eV}$ for $\mathrm{Cs}$ and $\mathrm{Sr}$, respectively.

The k-point convergence was accomplished with a gamma-centered mesh grid using $5 \times 5 \times 1$ k-points for the $4 \times 4$ hexagonal supercell described below for graphite. For these settings, energy was found to converge within $1 \mathrm{meV} /$ atom. For all other supercells, the size of the meshgrid was adjusted to keep the density of k-points in reciprocal space as constant as possible. The structures under investigation were arranged in supercell slab geometries with at least $9 \AA$ of vacuum normal to the adsorbing surface, which we take as the basal plane for graphitic materials.

Three different structures were studied in this work: graphite, amorphous carbon and diamond. Calculations on pristine graphite simulate adatom sorption in a $4 \times 4$ in-plane supercell of the primitive 2-atom in-plane cell, yielding 32 atoms in each of three graphene layers for a total of 96 atoms. The in-plane dimension of this cell after relaxation was $9.84 \AA$ in both directions. Simulations for graphite with armchair and zigzag edge defects were performed using upper graphene layers of 28 and 24 atoms, respectively, instead of a complete top layer of 32 atoms (two complete layers of graphene were used under the partial graphene layer). To study intercalation into graphite a four layer periodic graphite cell was used, each layer consisting of 32 atoms. For simulations involving pristine graphite, all carbon atoms and cell vectors were allowed to fully relax. The separation between consecutive graphene layers is $3.35 \AA$. For the graphite intercalation simulations all atoms were allowed to relax, as was the cell vector normal to the basal planes, but the in-plane cell vectors were held fixed. For the graphite adatom simulation, all atoms were allowed to relax but all the cell vectors were held fixed. Simulations performed on the reconstructed (111), (100) and the unreconstructed (110) diamond surfaces were conducted using 96 atoms, with the lower two carbon layers fixed in all directions. All other atoms were allowed to fully relax with the cell vectors held fixed. Adatom coverage for the diamond structures was of 1 adatom per 24 surface atoms for the diamond (100) and (110) surfaces and 1 adatom per 16 surface atoms for the diamond (111) surface. A vacuum layer of at least $10 \AA$ was used to separate surfaces for all the diamond simulations.

Initial atomic configurations for amorphous carbon structures were calculated with molecular dynamics (MD) using a slab composed of about one million atoms [30, 31]. Amorphous carbon structures were obtained using the second generation Reactive Empirical Bond-Order (REBO) potential [32]. The amorphous samples were prepared as described in Ref. [31]. Rectilinear samples having a width and length of $10 \AA$ and a depth of $6 \AA$ were taken from the surface of the MD obtained amorphous carbon slab. We will refer to the original surface as the surface of this sample, while the other faces, although technically also surfaces, will simply be called faces. Multiple cells of the amorphous carbon surface where chosen in order to get adequate sampling of different binding environments. A total of six different amorphous carbon surfaces with an average of 88 atoms each were used in the simulations. Surface sites having different sp2/sp3 ratios as well as surfaces having different atomic distributions were selected for binding. Cs and $\mathrm{Sr}$ adatoms were placed on top of all these different sites with the objective of finding the sites with the strongest binding. Since the amorphous carbon structure is characterized by significant atomic disorder, supercells did not have periodicity. In order to model these structures in a periodic cell a vacuum of $9 \AA$ was used in the direction normal to the surface plane while a 
vacuum of 4 was used in all other directions, normal to the other faces. Atoms within $1 \AA$ of the edges of the cubic samples were fixed, with the exception of the atoms on the upper face (the surface) of the slab. Binding energies were calculated following the equation:

$E_{b}=E_{c}+E_{a}-E_{s y s}$

where $\mathrm{E}_{\mathrm{c}}$ is the energy of the isolated carbon system, $E_{a}$ is the energy of a single isolated sorbate atom calculated fully spin polarized and $E_{s y s}$ is the total energy of the sorbatecarbon system. Note that $E_{b}>0$ corresponds to an atom being more stable sorbed into the carbon than as an isolated atom.

\subsubsection{DFT Results}

Table 3 presents the binding energies calculated in this research for Cs and Sr sorption on the different carbon structures. Analysis of results will be discussed for each surface on separate basis.

Graphite surfaces: The first three structures presented in Fig. 3 correspond to pristine graphite, graphite with vacancies, and graphite with Stone-Wales defects. Figure 5 shows the corresponding atomic structures used in the simulations. For the case of a vacancy defect, Fig. 5(c), a vacant site in the top most graphene layer can be observed while for the case of the Stone-Wales defect, Fig. 5(d), carbon atoms abandon the typical hexagonal configuration to form two heptagons and two pentagons.
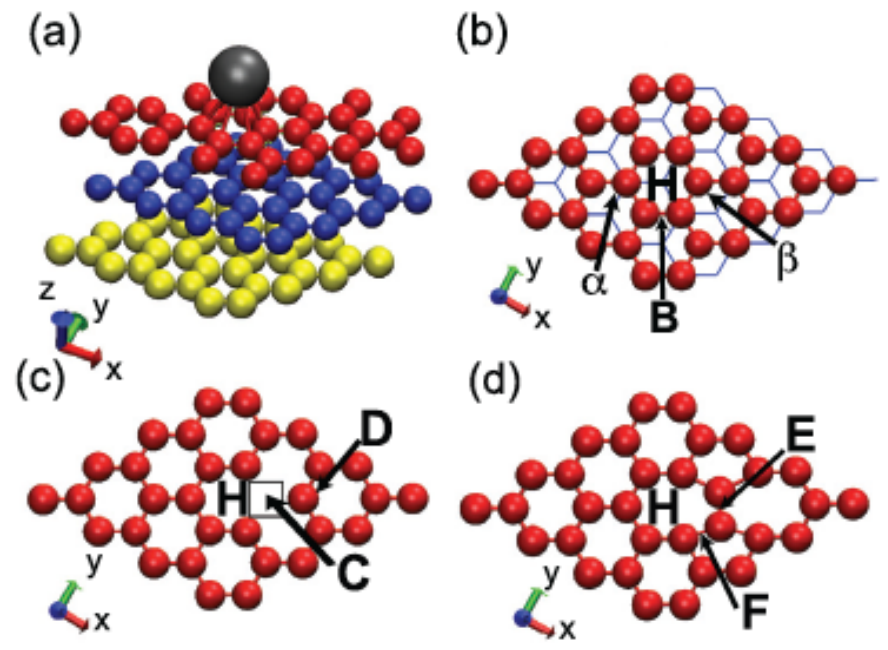

Figure 5. Pristine graphite structure with Cs adatom on the hollow (H) site. (b) Top two graphene layers for pristine graphite. Top most layer with (c) a vacancy (open square) and (d) Stone-Wales defects. 


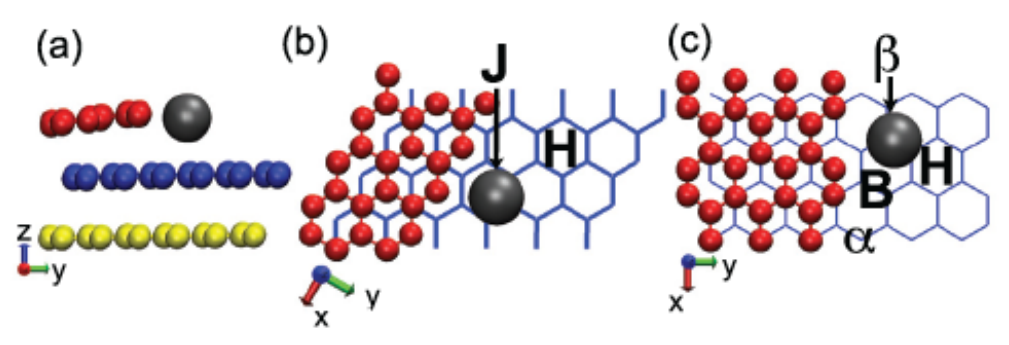

Figure 6. (a) Cs adatom on graphite with zigzag defect. Top most layers for (b) zigzag and (b) armchair edge defects in graphite.

Results in Table 3 show that Cs binds stronger than Sr to pristine graphite and the preferred binding site for both adatoms is the hollow region at the center of the $\mathrm{C}$ hexagon. It is also observed from the results that both adatoms bind more strongly to graphite with vacancies and Stone-Wales defects than they bind to pristine graphite and that, of all graphite surface structures considered, adatoms bind the most strongly to graphite with a vacancy defect. A third point of interest is that the strength of adatom binding varies with adatom type as well as with the surface to which the adatom is binding. This dependence reflects the importance of both the characteristics of each adatom as well as the different carbon structures on the strength of the binding.
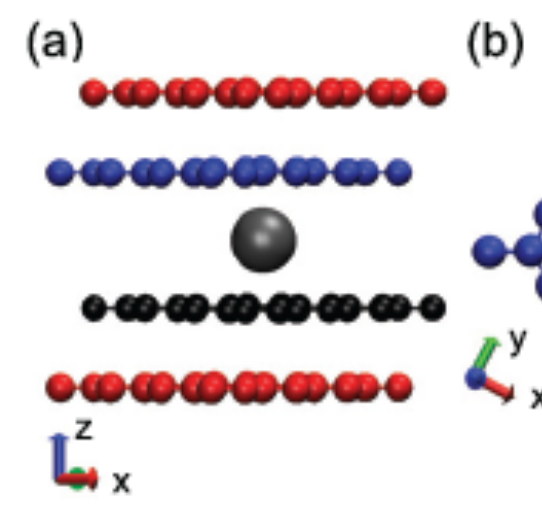

(c)

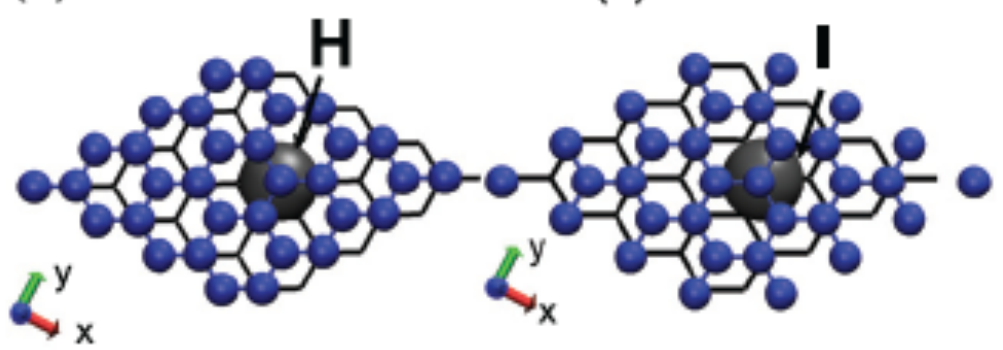

Figure 7. (a) Cs adatom on graphite with intercalation defect. (b)-(c) Preferred binding locations (only two middle layers depicted in figure).

Graphite edges: Figure 6 (a) presents a front view of an adatom on a structure with an armchair defect and Figs. 6 (b) and (c) present a top view of simulated graphite structures having zigzag and armchair defects respectively. Results in Table 3 show that binding energies for structures with edge defects are considerably higher than those for pristine graphite. Compared to pristine graphite, binding energies on structures with edge defects are about 2.9 and $5.8 \mathrm{eV}$ larger for Cs and Sr respectively, while binding energies are about 1.4 and $2.6 \mathrm{eV}$ larger for Cs and Sr respectively for the structure with the zigzag edge defect. Summarizing these results for simple adsorption on graphite, the results show an expected tendency of adatoms to bind more strongly to defect sites than pristine graphite. 


\begin{tabular}{|c|c|c|c|c|c|}
\hline & & \multicolumn{2}{|c|}{ Cs } & \multicolumn{2}{|c|}{$\mathrm{Sr}$} \\
\hline Structure & Site & $\mathbf{E}_{\mathbf{b}}$ & $\mathbf{Z}$ & $\mathbf{E}_{\mathbf{b}}$ & $\mathbf{Z}$ \\
\hline \multirow[t]{4}{*}{ Graphite } & $\mathbf{a}$ & 1.677 & 2.857 & 1.049 & 2.449 \\
\hline & b & 1.685 & 2.832 & 1.043 & 2.421 \\
\hline & Bridge (B) & 1.697 & 2.823 & 1.032 & 2.416 \\
\hline & Hollow $(\mathrm{H})$ & 1.752 & 2.790 & 1.151 & 2.401 \\
\hline \multirow[t]{2}{*}{ Graphite vacancy } & C & 2.671 & 2.695 & 3.641 & 2.079 \\
\hline & D & 2.521 & 3.018 & 1.943 & 2.933 \\
\hline \multirow[t]{2}{*}{$\begin{array}{l}\text { Graphite Stone- } \\
\text { Wales }\end{array}$} & $\bar{E}$ & -- & -- & 2.519 & 1.711 \\
\hline & $\mathbf{F}$ & 2.111 & 2.485 & -- & -- \\
\hline \multirow{3}{*}{$\begin{array}{l}\text { Graphite zigzag } \\
\text { edge defect }\end{array}$} & Hollow (H) & 2.108 & 2.429 & 1.965 & 2.051 \\
\hline & Hollow $(\mathrm{H})$ & -- & -- & 6.845 & -0.551 \\
\hline & $\mathbf{J}$ & 4.532 & 0.023 & -- & -- \\
\hline \multirow{4}{*}{$\begin{array}{l}\text { Graphite } \\
\text { armchair edge }\end{array}$} & $\mathbf{a}$ & 3.060 & -0.094 & -- & -- \\
\hline & $\mathbf{b}$ & 3.029 & -0.073 & -- & - \\
\hline & Bridge (B) & 3.167 & -0.061 & 4.157 & -0.587 \\
\hline & Hollow (H) & -- & -- & 4.266 & -0.661 \\
\hline \multirow{2}{*}{$\begin{array}{l}\text { Graphite } \\
\text { intercalation }\end{array}$} & Hollow (H) & 1.669 & -- & 1.967 & -- \\
\hline & I & 1.977 & -- & 2.183 & -- \\
\hline \multirow[t]{2}{*}{$\begin{array}{l}\text { Amorphous } \\
\text { carbon }\end{array}$} & -- & $3.507+/-0.396$ & -- & $\begin{array}{c}4.676+/- \\
1.299 \\
\end{array}$ & -- \\
\hline & & {$[3.045,3.952]$} & {$[3.348,2.728]$} & {$[2.497,6.137]$} & {$[0.884,0.987]$} \\
\hline \multirow[t]{3}{*}{ Diamond (100) } & $\mathbf{K}$ & 3.564 & 2.501 & 4.928 & 1.680 \\
\hline & Bridge (B) & 3.328 & 3.225 & 4.060 & 2.321 \\
\hline & $\mathbf{L}$ & 3.390 & 3.062 & 4.300 & 2.100 \\
\hline Diamond (111) & Hollow $(\mathrm{H})$ & 2.762 & 2.414 & 2.820 & 1.813 \\
\hline \multirow[t]{3}{*}{ Diamond (110) } & $\mathbf{M}$ & 3.472 & 2.730 & 4.676 & 2.004 \\
\hline & $\mathbf{N}$ & 3.276 & 3.055 & -- & -- \\
\hline & Bridge (B) & 3.272 & 3.0612 & -- & -- \\
\hline
\end{tabular}

Table 3. Binding energies (eV/atom) with respect to isolated atoms for $\mathrm{Cs}$ and $\mathrm{Sr}$ on different carbon based structures. Adatom adsorption heights z ( $\mathrm{A})$ with respect to top most carbon surface also provided. For amorphous carbon, the average binding energy and energy range is presented. 
Graphite intercalation: For the case of $\mathrm{Cs}$ and $\mathrm{Sr}$ intercalation, binding energies are weaker than for the case of graphite with defects, with the exception of Stone-Wales defects, where values are comparable. Figure 7 presents the simulated structure for Cs intercalation in graphite, where an increased separation of the layers due to the insertion of the large Cs atom can be seen.

Amorphous carbon surfaces: Table 3 presents simulation results for Cs an Sr binding on amorphous carbon surfaces. In the table, the average binding energy and its standard deviation, as well as the range of values taken by these energies (written as [min value, max value]), is presented. The range of binding energies for Cs and $\mathrm{Sr}$ on amorphous carbon reflects the fact that there are many distinct sites for binding.

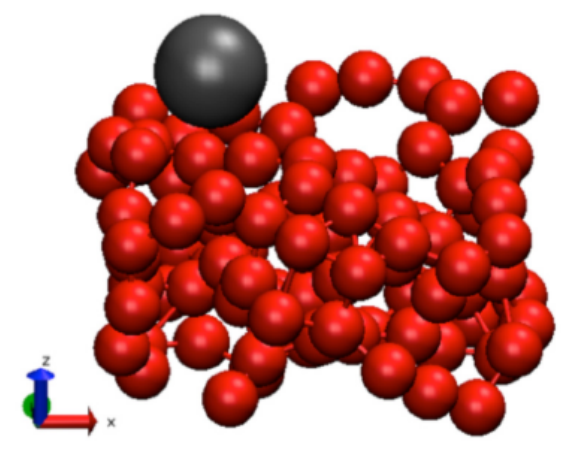

Figure 8. Amorphous carbon structure with Cs adatom on top.

Figure 8 shows one of the small cell samples used for DFT calculations with a Cs atom adsorbed on the surface. The original amorphous carbon bulk system from which samples were taken had a sp3 (sp2) fraction of 70\% (30\%). This implies that although most of the bonds on the material are sp3, the presence of $\mathrm{sp} 2$ bonds may lead to a different behavior of the surface from that of sp3 diamond. Results show that binding energies on amorphous carbon are higher than for the case of pristine graphite and for graphite intercalations. These results demonstrate that the presence of $\mathrm{sp} 3$ bonds as well as the disordered structure of amorphous carbon favor stronger binding than more graphitic surfaces.

Diamond surfaces: Figures 9 to 11 show the three low-index diamond surfaces (100), (111) and (110), respectively. Overall, we find that binding energies for Cs and Sr to diamond surfaces are considerably higher than on pristine graphite and for graphite intercalation. Binding energies are in the same range for (100) and (110) surfaces while they are the lowest for the (111) surface. These results are similar to those on amorphous carbon structures in that they also suggest that adatoms exhibit strong binding to structures with sp3 bonds. 


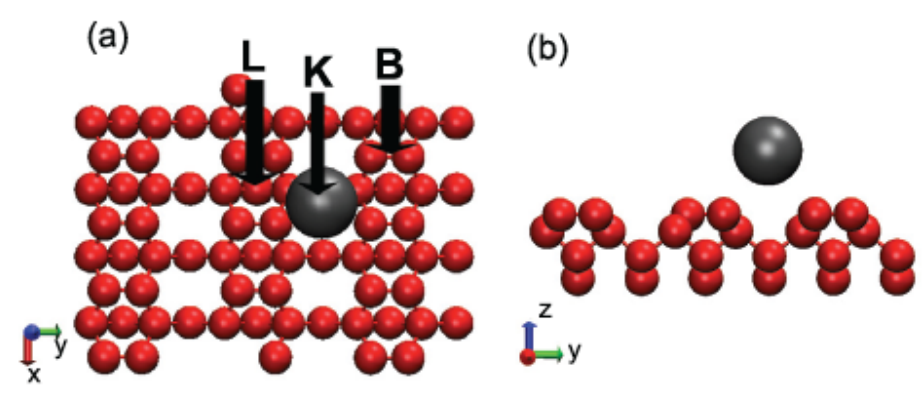

Figure 9. (a) Diamond 100 structure with Cs adatom on top. (a) Top view including the three top most upper layers (b) Side view of structure showing four top most layers.

(a)

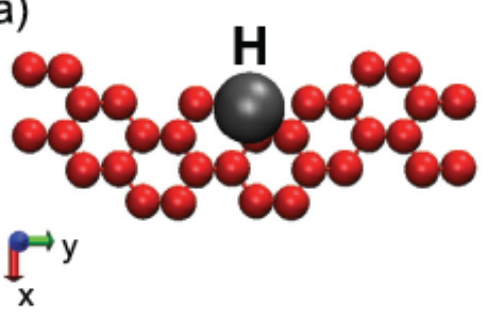

(b)

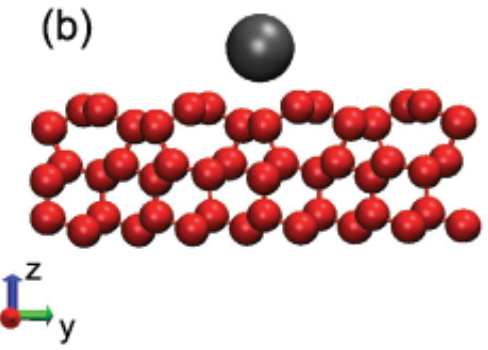

Figure 10. Reconstructed diamond (111) structure with Cs adatom on top. (a) Top view of top most layer. (b) Side view of structure showing three top most layers.

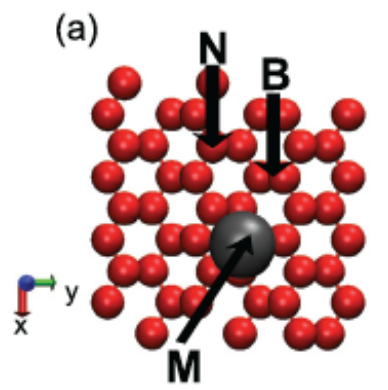

(b)

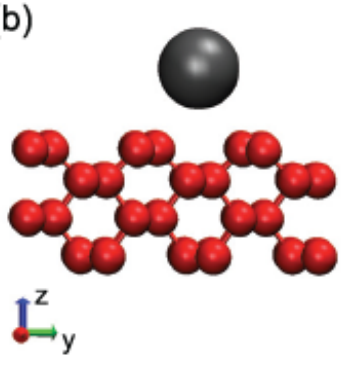

Figure 11. (a) Diamond (110) structure with Cs adatom on top. (a) Top view including the three top most upper layers. (b) Side view of structure showing four top most layers.

\section{Effect of adatom electronic structure on binding strength}

Figure 12 shows a plot of Sr binding energies as a function of Cs binding energies for the different materials. It is observed from the figure that the binding energies for $\mathrm{Cs}$ and $\mathrm{Sr}$ approximately follow a linear relation. This relation can be well described by the equation $E_{b}(S r)=2 E_{-} b(C s)+E_{0}$, where $E_{b}(C s)$ and $E_{b}(S r)$ are the binding energies of Cs and $S r$, respectively. $E_{0}$ is a constant which, from fitting the data with a line with a slope of 2 , was found to be $\mathrm{E}_{0}=-2.2$. In this equation, the slope of 2 may be explained by the fact that $\mathrm{Sr}$ has 
two valence electrons compared to one of $\mathrm{Cs}$, while the intercept $\mathrm{E}_{0}$ may be viewed as an offset related to the differing electronegativities and atomic stabilities of Sr and Cs. In Fig. 12 the binding energies for amorphous carbon show a larger spread around the linear relationship than the higher symmetry structures. We believe that this larger spread is due to the lower symmetry sites allowing somewhat different local relaxations for the different binding atoms, introducing terms into the binding energy that are not dominated by electron transfer.

The very strong correlation between $\mathrm{Cs}$ and $\mathrm{Sr}$ binding and their number of valence electrons suggests that binding occurs through donation of their valence electrons, and is therefore largely ionic in character. This aspect of the bonding was further confirmed by electron localization function (ELF) analysis performed on graphite, amorphous carbon and the diamond structure. This analysis showed no electron localization between the adatom and the carbon atoms on the surface. The absence of such localization is indicative of limited covalent bonding between the atoms [33].

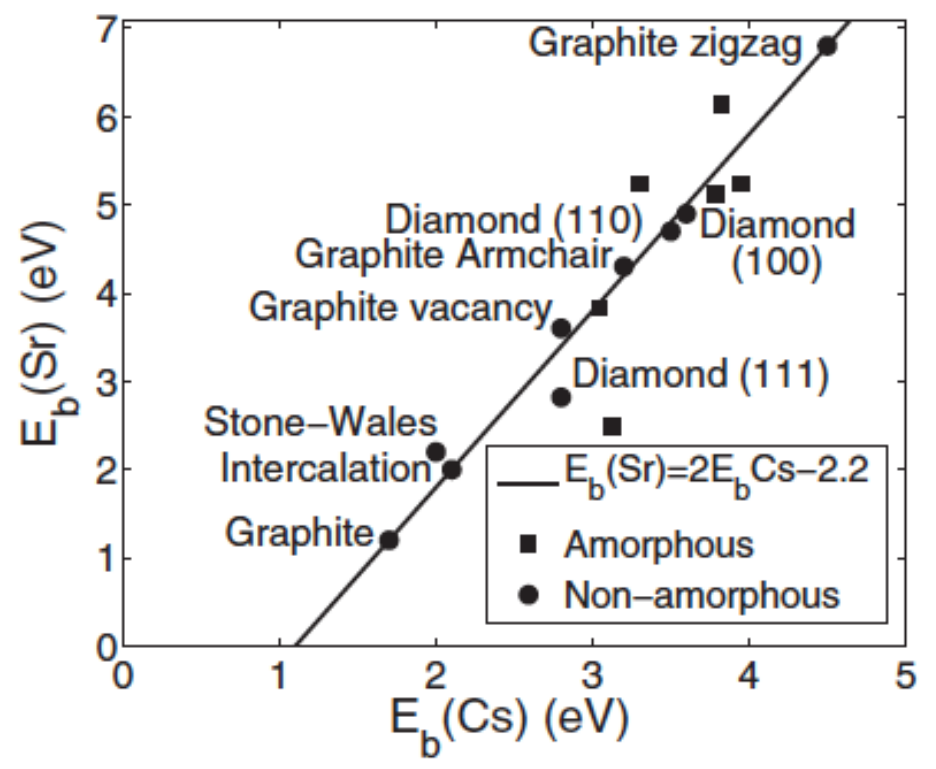

Figure 12. Sr binding energy as a function of Cs binding energy.

In order to more clearly understand the nature of the ionic bonding that seems to dominate the $\mathrm{Sr}$ and $\mathrm{Cs}$ binding, Bader charge analysis [34] was used to study the charge transfer between the adatoms and the different carbon structures (Table 4). Charge transfer values for amorphous carbon presented in the table are given only for the site with the strongest Cs and Sr binding. It is observed from the table that for all examined structures, adatoms donate charge to the surface. For the case of Cs there is an average charge transfer of $0.86+/-0.016$ electrons, while for the case of $\mathrm{Sr}$ transfer is on average 1.43+/-0.082 electrons (for Sr we exclude the case of pristine graphite which we discuss below). The greater charge transfer from $\mathrm{Sr}$ is consistent with it having two valence electrons as opposed to the single valence electron for Cs. The large charge transfer values presented in 
Table 4 further support a predominantly ionic character to the adatom binding. For the case of Cs binding on graphite, work by other authors $[35,36]$ has also identified binding to be ionic.

A clear exception to the interpretation of Sr donating two electrons and Cs donating just one is the Bader charge analysis of Sr binding to pristine graphite, where only 0.90 electrons are transferred by $\mathrm{Sr}$ and 0.87 are transferred by Cs. The change to just one electron donation from $\mathrm{Sr}$ is presumably due the graphite surface being insufficiently electronegative to pull the second electron from Sr. For cases where Cs and Sr both donate one electron we hypothesize a relationship between binding energies of the form $E_{b}(S r)=1 E_{b}(C s)+E_{-}$, where $E_{1}$ is a different constant than $E_{0}$. Fitting to just the binding energy for pure graphite yields $\mathrm{E}_{1}=-0.60$.

This analysis suggests that for weakly bonding carbons, where $\mathrm{Sr}$ transfers only one electron, there would be a different line describing the $\mathrm{Sr}$ and Cs relative binding strength than that shown in Fig.12. Under this hypothesis the fact that the Cs and Sr binding for pure graphite fall on the line shown in Fig 12 is just coincidence, as these energies are actually governed by different levels of Sr charge transfer than the others in the figure. However, as we have only one surface yielding single electron transfer from $\mathrm{Sr}$, further study is needed to verify this hypothesis.

\begin{tabular}{|l|c|c|}
\hline & \multicolumn{2}{|c|}{ Donated Charge } \\
\hline \multicolumn{1}{|c|}{ Structure } & Cs Adatom & Sr Adatom \\
\hline Graphite & 0.87 & 0.90 \\
\hline Graphite Vacancy & 0.84 & 1.36 \\
\hline Graphite Stone-Wales & 0.85 & 1.39 \\
\hline Graphite Zigzag & 0.84 & 1.46 \\
\hline Graphite Armchair & 0.87 & 1.46 \\
\hline Graphite Intercalation & 0.85 & 1.48 \\
\hline Amorphous Carbon & 0.88 & 1.51 \\
\hline Diamond (100 & 0.88 & 1.49 \\
\hline Diamond (111) & 0.85 & 1.25 \\
\hline Diamond (110) & 0.86 & 1.45 \\
\hline
\end{tabular}

Table 4. Charge transferred from adatom to surface as calculated by the change in Bader charge from the isolated adatom to the sorbed adatom.

By comparing values in Tables 3 and 4, we find that charge transfer remains approximately constant (except for $\mathrm{Sr}$ on perfect graphite) while values of binding energies can vary dramatically. The above results strongly support the hypothesis that the sorbed atoms are donating electrons to the carbon structures, which would imply that the source of binding energy differences for similar levels of charge donation must be the stability of the transferred electrons in the carbon structure. We therefore propose that it is the presence of stable electron states in the carbon structures that governs the strength of the binding. This hypothesis is consistent with the fact that structures with low or zero dangling bond density (pristine graphite, graphite with Stone-Wales and intercalation defects) tend to lead 
to weaker binding energies than structures having a high density of dangling bonds (diamond (100), diamond (111) and diamond (110)), as can be seen in Fig. 13. The presence of dangling bonds provides highly stable states for the donated electrons, enhancing the binding energy.

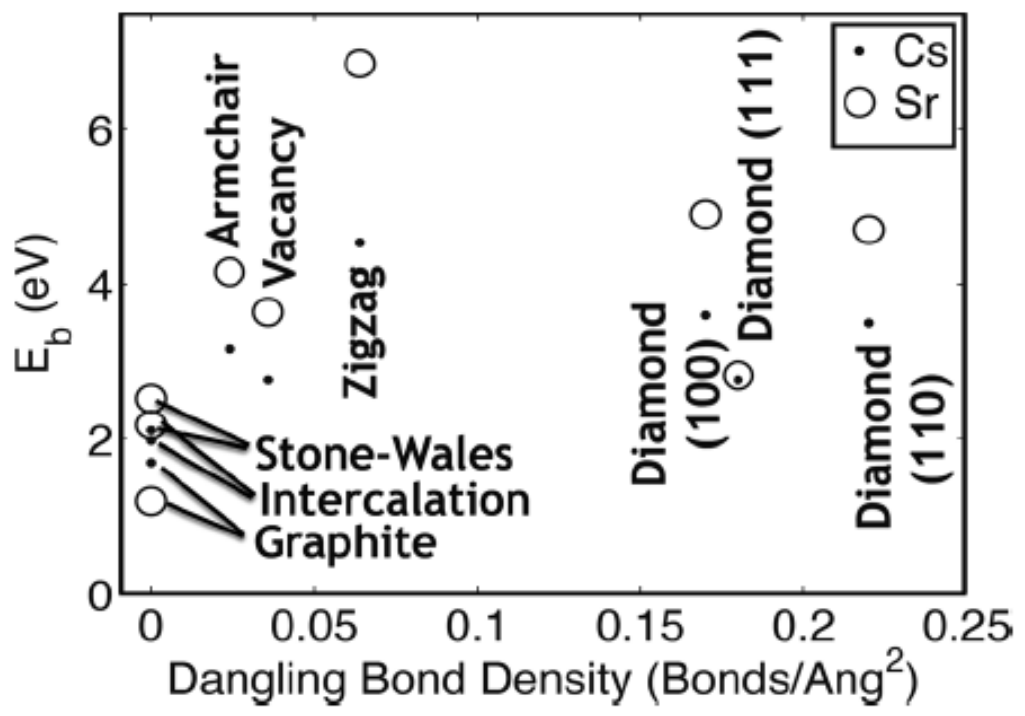

Figure 13. Binding energy as a function of dangling bond density.

\subsubsection{Comparison between DFT and experimental results}

In this section, a comparison between simulation results and experimental measurements for Cs and Sr sorption on carbon structures is presented. In particular, simulation results are compared to experimental binding energies extracted from sorption isotherms for irradiated and unirradiated nuclear graphite, coke and fuel matrix material. Experimental results originated from Knudsen cell measurements performed in a vacuum chamber by General Atomics $[6,15,21]$. Specifically, we report experimental binding energies for $\mathrm{T}=0 \mathrm{~K}$ extracted from sorption isotherms at $973 \mathrm{~K}$ and $1373 \mathrm{~K}$. Table 5 summarizes the experimental data. It can be seen from the table that there is more available data for Cs. However, results presented in Table 3 and Fig. 12 suggest that Cs and Sr exhibit strongly correlated binding behavior on the different carbon structures.

The materials presented in Table 5 have different atomic structures: nuclear graphite is dominated by sp2 bonds, while coke and fuel matrix material contain a combination of sp2 and sp3 bonds. From the available experimental data it can be observed that both $\mathrm{Cs}$ and $\mathrm{Sr}$ bind more strongly to surfaces with a combination of $\mathrm{sp} 2$ and sp3 bonds than they bind to sp2 graphite. It is also important to note that extracting the binding energies at zero Kelvin from sorption isotherms developed for isotherms at higher temperatures introduces errors and some trends between materials are lost. For example it is observed that at zero Kelvin the binding energy of unirradiated graphite is higher than that of its irradiated counterpart, which, as will be discussed below, is not consistent with the observed high-temperature behavior. However, even at zero Kelvin the behavior of binding energies is still similar 
enough to the behavior at higher temperatures to allow for a qualitative comparison with DFT results.

\begin{tabular}{|l|c|c|}
\hline & \multicolumn{2}{|c|}{$\mathbf{E}_{\mathbf{b}}(\mathbf{e V} / \mathbf{a t o m})$} \\
\hline Material & $\mathbf{C s}$ & $\mathbf{S r}$ \\
\hline Graphite H-327 & $2.30(0 \mathrm{~K})$ & 4.491 \\
\hline & $2.74(973 \mathrm{~K})$ & -- \\
\hline Graphite H-451 Unirradiated & $2.92(1373 \mathrm{~K})$ & -- \\
\hline & $2.01(0 \mathrm{~K})$ & -- \\
\hline & $2.92(973 \mathrm{~K})$ & -- \\
\hline Graphite H-451 Irradiated & $3.30(1373 \mathrm{~K})$ & -- \\
\hline & $1.41(0 \mathrm{~K})$ & -- \\
\hline & $3.00(973 \mathrm{~K})$ & -- \\
\hline Fuel Rod Matrix & $3.65(1373 \mathrm{~K})$ & -- \\
\hline & $2.81(0 \mathrm{~K})$ & 5.160 \\
\hline & $3.03(973 \mathrm{~K})$ & -- \\
\hline Coke & $3.12(1373 \mathrm{~K})$ & -- \\
\hline
\end{tabular}

Table 5. Experimental values of binding energies for Cs and Sr on selected carbon based structures $[6,15]$.

Figure 14 presents a comparison between DFT calculated binding energies and the experimental values presented in Table 5 for Cs. The shaded region in the figure corresponds to the range of experimental values. Figure 15 presents a similar comparison for Sr. It is observed from the figures that both $\mathrm{Cs}$ and $\mathrm{Sr}$ exhibit similar trends for different carbon structures even if experimental information for $\mathrm{Sr}$ is more limited.

In comparing to experiments, first we consider the case of pristine and defected graphite, ignoring for the moment the sp3 containing structures of amorphous $\mathrm{C}$ and diamond. For the case of Cs and Sr, pristine graphite, graphite with intercalation, and Stone-Wales defects all have weaker binding than reported by experiments, while a zigzag edge has binding energies that are stronger than in experiments. However, vacancies and armchair defects in graphite provide binding energies relatively close to the experimental values. The weak binding to pristine graphite, either on the surface or through intercalation, strongly suggests that pristine graphite does not play a dominant role in the Cs or Sr sorption. Although uncertainties in the experimental results and the calculations do not allow rigorous identification of the binding site, these results strongly suggest that $\mathrm{Cs}$ and $\mathrm{Sr}$ sorption on graphite is dominated by binding to defects in the structure. 


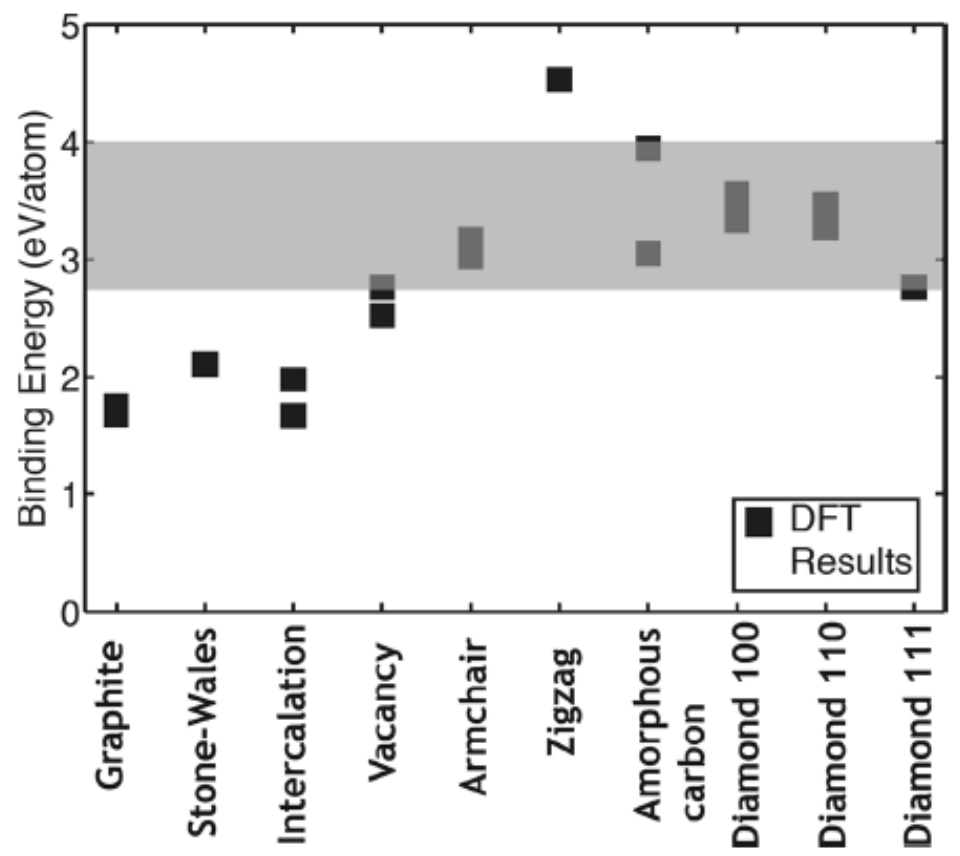

Figure 14. Calculated binding energies for Cs sorption on carbon structures. Shaded region corresponds to experimental value range.

The possibility that vacancies enhance sorption has been proposed to explain experimental results that show stronger binding energies in irradiated samples. In particular, neutron irradiation is known to create defects in graphite, including vacancies [37, 38], and these vacancies have been proposed as the cause of the increased sorption seen in irradiated graphite. The interpretation provided by Apperson et al. [37] is consistent with findings from our calculations, since simulation results predict that increased vacancy concentrations will lead to increased numbers of strong binding sites.

We have also considered the role of the amorphous carbon and diamond sp3 containing phases in sorption. It can be observed from Figs. 14 and 15 that DFT binding energies for amorphous carbon are within the range of those obtained experimentally for both Cs and Sr. In particular, binding energies for amorphous carbon are comparable to those for fuel rod matrix, a material characterized by a combination of $\mathrm{sp} 2$ and sp3 bonds. For the case of diamond, a pure sp3 structure, binding energies are also within experimental range (excluding the diamond (111) for the Sr system). While pure diamond phases are not likely to exist in HTR in significant quantities, this limiting case demonstrates that sp3 carbon can provide very strong binding sites, many within the range of experimental observations. The strong binding energies on amorphous carbon and diamond are also in agreement with experimental observation linking coke rich-amorphous carbon structures with sp3 phases to strong binding energies [39]. Experimental binding energies presented in Table 5 are consistent with DFT results for structures characterized by sp3 or a combination of sp2 and sp3 bonds. This result suggests that, along with defect sites on graphite, sorption in carbon will be dominated by structures containing a significant fraction of sp3 bonds. 


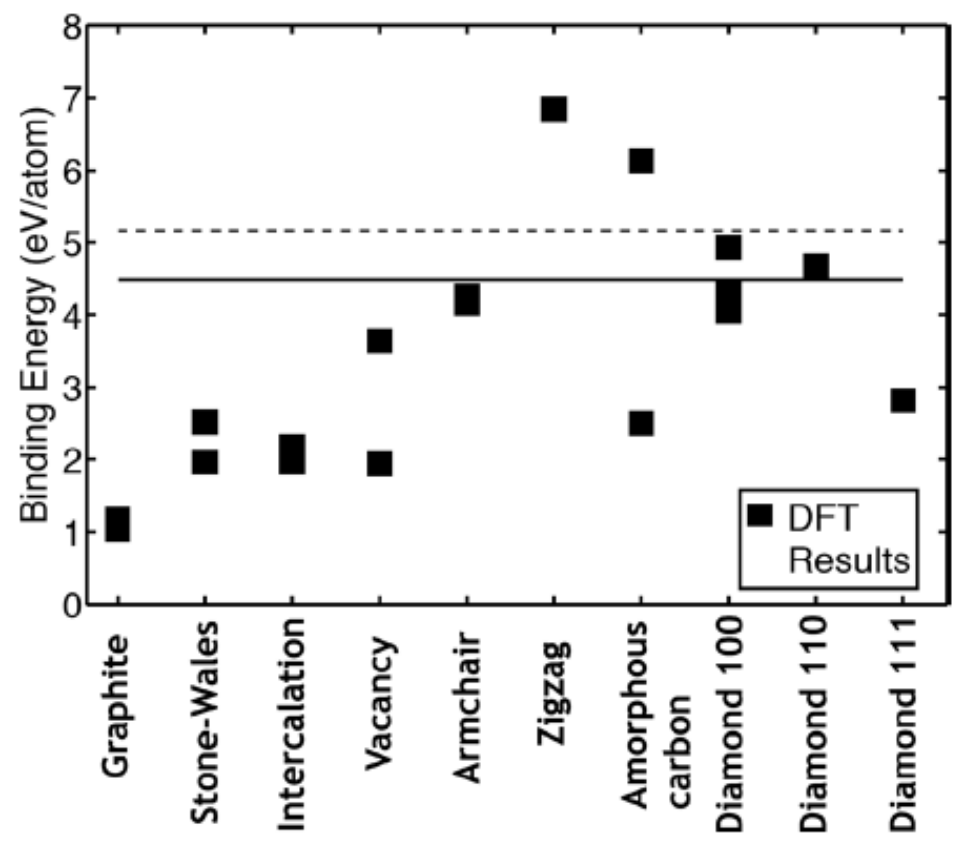

Figure 15. Calculated binding energies for Sr sorption on carbon structures. Continuous line in the figure corresponds to isotherm for unirradiated nuclear graphite while dashed line corresponds to unirradiated fuel rod matrix.

\subsubsection{DFT Based sorption isotherms}

This section presents the derivation of the isotherm models based on DFT binding energetics. In particular, the model was derived for the case of isolated fission product Cs on the graphite surface and for the case where this fission product competes with other species for surface sites. The purpose of the later is to serve as a first approximation to simulate fission product sorption under air ingress accident conditions. With this in mind, isotherms for the sorption of fission product $\mathrm{Cs}$ in the presence $\mathrm{O}_{2}$ and $\mathrm{Cs}_{2} \mathrm{O}$ were calculated. Although other Cs species might also be present in the system in the case of air ingress, both our simulations and experimental results suggest that $\mathrm{Cs}_{2} \mathrm{O}$ will be the dominant oxide in the system [40-42].

The sorption isotherm model presented in this study is constructed by minimizing the Grand Canonical (GC) thermodynamic potential for the carbon surface interacting with an external gas source $[43,44]$. Given a surface with $n$ sites of type $\mathrm{A}$, a single $\mathrm{Cs}$ or $\mathrm{O}_{2}$ atom occupies only one single site $\mathrm{A}$ in carbon, while a single $\mathrm{Cs}_{2} \mathrm{O}$ molecule occupies two sites AA. For a system where one fission product occupies two sites (A-A) and all other species occupy one site (A) on the surface, the GC potential can be approximately written as:

$$
G=C_{1} E_{1}+\left(1-C_{1}\right)\left(\sum_{i=2}^{n} C_{i} E_{i}+C_{v} E_{v}\right)-T S_{\text {conf }}-C_{1} \mu_{1}-\left(1-C_{1}\right) \sum_{i=2}^{n} C_{i} \mu_{i}-C_{C} \mu_{C}
$$


where $C_{1}$ is the concentration of the fission product occupying two sites (i.e. $\mathrm{Cs}_{2} \mathrm{O}$ ), $C_{i}$ for $\mathrm{i}>1$ is the concentration of all other species in the system (i.e. Cs and $\mathrm{O}_{2}$ ). The terms $E_{i}$ correspond to the total energy for each of these species as obtained from independent VASP calculations. In the equation, $T$ is the temperature and $m_{i}$ is the chemical potential of the different species in their source state. The term $E_{v}$ in the equation corresponds to the total energy of the isolated system with no species bound to the surface and $C_{v}$ is the concentration of unoccupied sites:

$C_{v}=1-\sum_{i=2}^{n} C_{i}$

The configurational entropy of the system is given by:

$S_{\text {conf }}=-k_{b}\left(\frac{C_{1}}{2} \ln C_{1}+\frac{\left(1-C_{1}\right)}{2} \ln \left(1-C_{1}\right)+\left(1-C_{1}\right)\left(\sum_{i=2}^{n} C_{i} \ln C_{i}+C_{v} \ln C_{v}\right)\right)$

where $k_{b}$ is the Boltzmann constant. Equations 6 and 8 are subject to the constraint:

$$
C_{1}+\left(1-C_{1}\right)\left(\sum_{i=2}^{n} C_{i}+C_{v}\right)=1
$$

In order to find the most stable configuration of the species on the surface, the GC potential of the composite system, Eq. 6, is minimized with respect to the concentration of the different species in the system. Replacing Eq. 8 into Eq. 5 and minimizing with respect to $C_{i}$ we obtain:

$$
\frac{C_{1}}{1-C_{1}}=\exp \left(-2 \beta\left(E_{1}-\mu_{1}-C_{v}\left(E_{v}-\frac{\ln C_{v}}{\beta}\right)-\sum_{i=2}^{n} C_{i}\left(E_{i}-\frac{\ln C_{i}}{\beta}-\mu_{i}\right)\right)\right)
$$

for $\mathrm{i}=1$, while for $\mathrm{i}>1$ we obtain:

$$
\frac{C_{i}}{C_{v}}=\exp \left(\beta\left(E_{b, i}+\mu_{i}^{*}\right)\right)
$$

where $E_{b, i}$ is the binding energy of element $i$ on the carbon surface. The term $m_{i}$ is defined as:

$$
\mu_{i}^{*}=\mu_{i}-E_{i}^{D F T}
$$

Where $m_{i}$ is obtained from tables and $E_{i} D F T$ is obtained from simulations. Total energies in Eqs. 10 and 11 are obtained from independent VASP calculations for each of the systems i.e. from simulations for each single species on carbon on the same binding site. For the case of graphite, we use the hollow region in the middle of a carbon hexagon as the binding site 
since it is the preferred binding site for $\mathrm{Cs}$ and $\mathrm{Cs}_{2} \mathrm{O}$ [45]. General equations for the sorption isotherms can also be obtained:

$$
\ln \left(\frac{P_{1}}{P_{0}}\right)=\left(\beta\left(E_{1}-\mu_{i}^{\prime}-C_{v}\left(E_{v}-\frac{\ln C_{v}}{\beta}\right)-\sum_{i=2}^{n} C_{i}\left(E_{i}-\frac{\ln C_{i}}{\beta}-\mu_{i}\right)\right)\right)+\frac{1}{2} \ln \left(\frac{C_{1}}{1-C_{1}}\right)
$$

for $i=1$. For the case $i>1$ we obtain:

$$
\ln \left(\frac{P_{i}}{P_{0}}\right)=\left(-\beta\left(E_{b, i}-\mu_{i}^{\prime}\right)\right)+\ln \left(\frac{C_{i}}{C_{v}}\right)
$$

Terms in Eqs. 13 and 14 are found via a combination of DFT for the binding energies and thermodynamic tables for the case $m_{i}^{\prime}$ of the isolated gases. Equations 12 an 13 are used to predict the competitive sorption behavior of $\mathrm{Cs}, \mathrm{Cs}_{2} \mathrm{O}$ and $\mathrm{O}_{2}$ on both graphite and amorphous carbon structures located in the enclosure of a reactor's vessel. Equation 13 is used for the case of $\mathrm{Cs}_{2} \mathrm{O}$ sorption while Eq. 14 is used for the case of $\mathrm{Cs}$ and $\mathrm{O}_{2}$ sorption. The species in the system that are not bound to the carbon core will be in the gas phase. Assuming ideal gas behavior, we have:

$$
P_{i} V=R T N_{i}
$$

Where $P_{i}$ is the gas partial pressure of species $i, V$ is the vessel free volume, $R$ is the gas constant, $T$ is the system temperature and $N_{i}$ is the mass of species $i$ that are in gas phase. In order to ensure chemical equilibrium between the species, the chemical potential must follow the relation:

$$
2 \mu_{C s}+\frac{1}{2} 2 \mu_{O_{2}}=\mu_{C s_{2} O}
$$

Figure 16 presents sorption isotherms for isolated Cs on graphite. The figure includes isotherms obtained using the thermodynamic model based on VASP calculations as well as the experimental isotherms calculated using the parameters in Table 2. One can see from the figure that when compared to experimental isotherms, the DFT based isotherms underpredict Cs sorption. For the case of graphite, this behavior is expected since binding energies for Cs on pristine graphite are below experimental values. In order to take into consideration the differences between DFT and experimental isotherms for the case of sorption on graphite, in our model we present two sets of results: (a) sorption isotherms using binding energies from DFT exclusively and (b) sorption isotherms using experimental binding energies for Cs and DFT binding energies for all other species. This combined approach provides a qualitative overall result for the sorption behavior on the different carbon structures. 


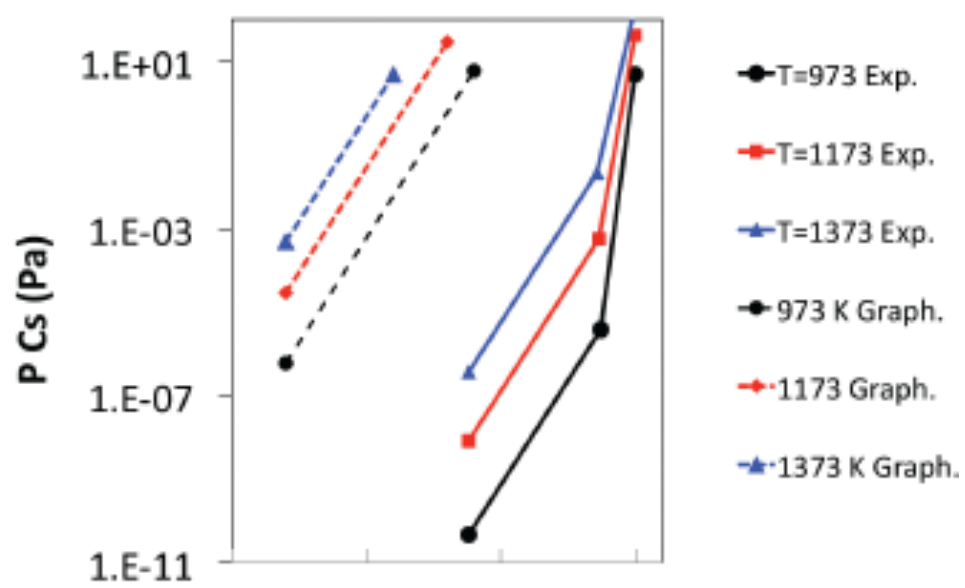

\section{E-13 1.E-08 1.E-03 1.E+02 $\left(\mu \mathrm{mol} \mathrm{Cs} / \mathrm{m}^{2}\right)$}

Figure 16. Cs sorption isotherms obtained from: experiments (Exp.) and using VASP calculations for graphite (Graph.).

\subsubsection{Case Study: Fission product sorption behavior during $\mathbf{0}_{2}$ ingress accident conditions on a reactor's vessel}

In order to investigate fission product sorption in a reactor environment, calculations to predict Cs inventories on the carbon core of a reactor's vessel enclosure were performed as part of this study. The enclosure used in these calculations is roughly based on the prismatic NGNP High Temperature Gas Reactor concept design [46]. The main parameters used in the calculations are presented in Table 6. The binding energies used in the calculations are summarized in Tables 7 and 8 . In the calculations, the system is modeled as a fixed volume enclosure containing a set amount of carbon (either graphite or amorphous carbon). It is assumed that a fixed mass of Cs is in the system. In this study, modeling is performed assuming low release (Low Cs) and high release (High Cs) conditions. Low release conditions were based on expected release values from a concept prismatic reactor [46] while high release conditions were based measured on release data for lower quality TRISO fuel particles [47]. As a first approximation to air ingress conditions, $\mathrm{O}_{2}$ was included in the system, along with $\mathrm{Cs}_{2} \mathrm{O}$ molecules, which is expected to be the main oxide with $\mathrm{Cs}$ that is formed [40-42]. Starting from this system, fission product sorption behavior was calculated for $\mathrm{P}_{02}=10^{-20}$ atm and $\mathrm{P}_{02}=0.2$ atm, which provides an approximate range of pressures that can be expected between operation and accident conditions [48]. The temperature range of interest for this work is between 600 and $1900 \mathrm{~K}$. This temperature range covers normal and expected accident conditions for the HTR reactor [49] while also including lower temperatures to understand limiting behavior. Note that the total number of moles of Cs binding sites are $1.1 \mathrm{~mol}$ on the graphite surface and $3.4 \mathrm{~mol}$ on the amorphous carbon surface. For the case of amorphous carbon, this is $3.8 \times 10^{3}$ the amount 
of Cs in the low Cs case $\left(1.2 \times 10^{3}\right.$ for the case of graphite) but just $2.2 \%$ of the Cs in the high Cs case $(0.7 \%$ for the case of graphite).

\begin{tabular}{|c|c|}
\hline Parameter & Value \\
\hline Vessel Volume $\left(\mathrm{m}^{3}\right)$ & 1200 \\
\hline Core Volume $\left(\mathrm{m}^{3}\right)$ & 500 \\
\hline Free Volume $\left(\mathrm{m}^{3}\right)$ & 500 \\
\hline Core Mass (kg) & 870,000 \\
\hline Cs content (mmol) & $\begin{array}{c}\text { 899(Low Cs) } \\
154 \times 10^{6} \text { (High Cs) }\end{array}$ \\
\hline$P_{02}$ (atm) & $10-20-0.2$ \\
\hline Temperature (K) & $600-1900$ \\
\hline $\begin{array}{l}\text { Graphite BET } \\
\text { Surf. Area }\left(\mathrm{m}^{2} / \mathrm{g}\right)\end{array}$ & 0.160 \\
\hline $\begin{array}{l}\text { Amorphous Carbon BET } \\
\text { Surface Area }\left(\mathrm{m}^{2} / \mathrm{g}\right)\end{array}$ & 0.500 \\
\hline
\end{tabular}

Table 6. Parameters used in model considering $\mathrm{O}_{2}$ ingress.

\section{DFT exclusive model- Graphite Core}

Here in this model, all binding energies used in the sorption Eqs. 13 and 14 are taken from DFT calculations and we consider just sorption to perfect graphite. Figures 17 to 19 present sorption behavior for the different species on the graphite core for $\mathrm{P}_{02}=10^{-20} \mathrm{~atm}$. In all following figures, series labeled $\mathrm{Cs}_{2} \mathrm{O}$ indicate moles of $\mathrm{Cs}$ in the form of $\mathrm{Cs}_{2} \mathrm{O}$ as a fraction of the total Cs in the system. Figure 17 presents species concentration on the carbon surface as mol fractions of total Cs, Fig. 18 presents the inventory of species in gas phase, also as mol fraction of total Cs. Finally, Fig. 19 presents the fraction of occupied sites on the carbon core. Results in Fig. 17 show that Cs binding to the surface is not significant. The figure does not have curves for $\mathrm{Cs}_{2} \mathrm{O}$ bound to graphite since weak binding leads to no surface sorption of $\mathrm{Cs}_{2} \mathrm{O}$ in this case. For the high concentration regime, most Cs remains in gas phase for temperatures above $1000 \mathrm{~K}$. For temperatures below $1000 \mathrm{~K}$, Cs binds to the surface but as temperature is lowered, most of the Cs inventory goes from atomic $\mathrm{Cs}$ to $\mathrm{Cs}_{2} \mathrm{O}$, which does not bind. A similar behavior is observed for the low concentration regime with the difference that the transition from $\mathrm{Cs}$ gas to $\mathrm{Cs}_{2} \mathrm{O}$ gas occurs at a lower temperature. Figure 19 shows that site occupation is almost negligible for the low concentration regime and very low for the high concentration regime. The figure again does not have curves for $\mathrm{Cs}_{2} \mathrm{O}$ bound to graphite at low Cs there is essentially no surface sorption in this case. 


\begin{tabular}{|l|c|c|c|c|}
\hline & \multicolumn{4}{|c|}{ Binding Energy (E $\mathbf{E}_{\mathbf{b}}$ ) } \\
\hline Site & $\mathbf{1}$ & $\mathbf{2}$ & $\mathbf{3}$ & $\mathbf{4}$ \\
\hline $\mathbf{C s}$ & 3.30 & 3.79 & 3.83 & 3.12 \\
\hline $\mathbf{C s}_{\mathbf{2}} \mathbf{O}$ & 6.40 & 4.75 & 7.35 & 5.84 \\
\hline $\mathbf{O}_{2}$ & 0.15 & -5.64 & -8.48 & 0.99 \\
\hline
\end{tabular}

Table 7. Element binding energies $\mathrm{E}_{\mathrm{b}}$ in $\mathrm{eV} /$ atom(molecule)) on amorphous carbon on four different sites.

\begin{tabular}{|c|c|c|}
\hline & \multicolumn{2}{|c|}{ Binding Energy $\left(\mathrm{E}_{\mathrm{b}}\right)$} \\
\hline & Pristine Graphite & Amorphous Carbon \\
\hline Cs & 1.74 & {$[3.12,3.83]$} \\
\hline Cs Exp1 & $2.57(600 \mathrm{~K})$ & $2.94(600 \mathrm{~K})$ \\
\hline & $3.20(2000 \mathrm{~K})$ & $3.26(2000 \mathrm{~K})$ \\
\hline $\mathrm{Cs}_{2} \mathrm{O}$ & 0.82 & {$[4.75,5.84]$} \\
\hline $\mathbf{O}_{2}$ & 0.08 & {$[-8.48 .1]$} \\
\hline
\end{tabular}

Table 8. Element binding energies ( $\mathrm{E}_{\mathrm{b}}$ in $\mathrm{eV} /$ atom(molecule)) on different carbon based structures. Binding energies for $\mathrm{Cs}, \mathrm{O}_{2}$ and $\mathrm{Cs}_{2} \mathrm{O}$ are calculated with respect to the isolated adatom or molecule.

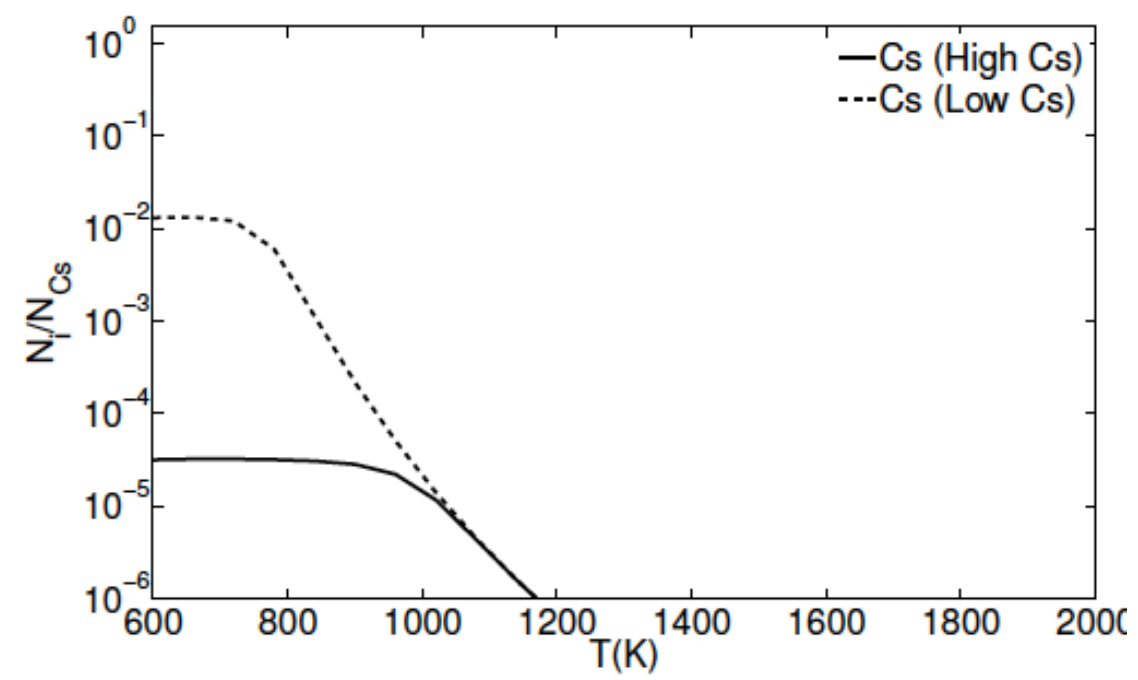

Figure 17. Inventory of species on graphite core for $\mathrm{P}_{02}=10^{-20} \mathrm{~atm}$. Simulation done with exclusively DFT energies. 


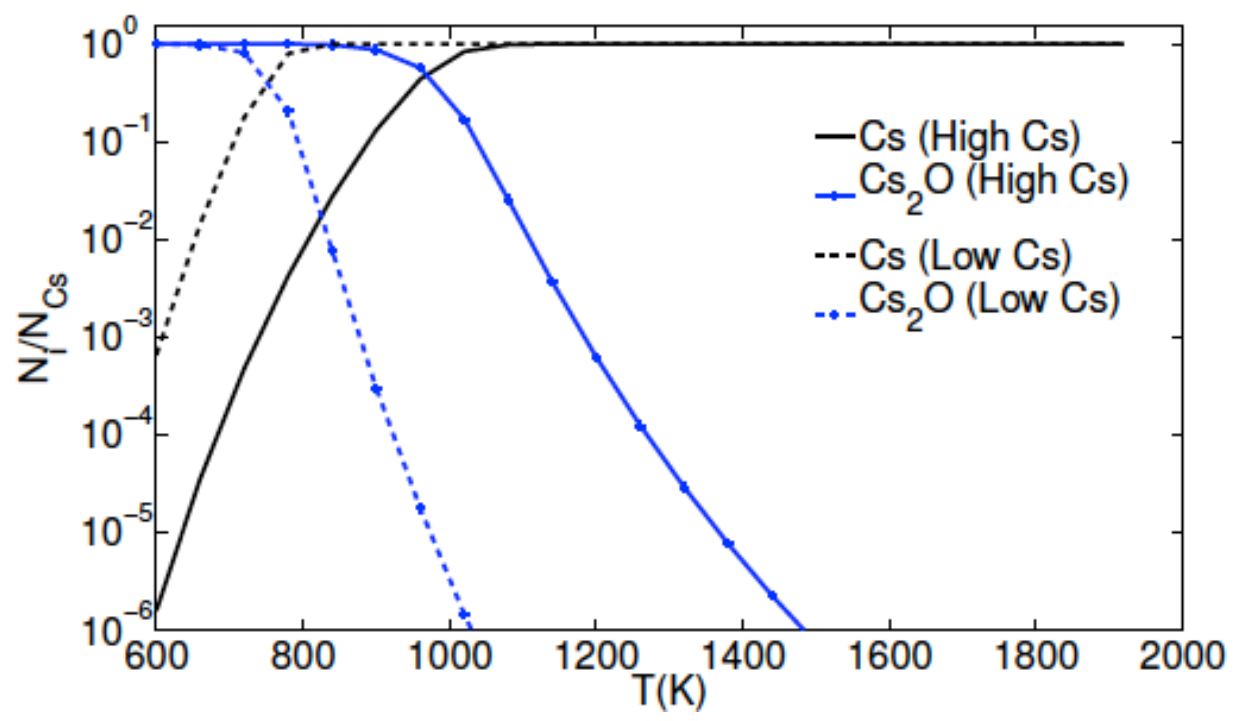

Figure 18. Inventory of species in gas phase $\mathrm{P}_{02}=10^{-20}$ atm. Simulation done with exclusively DFT energies.

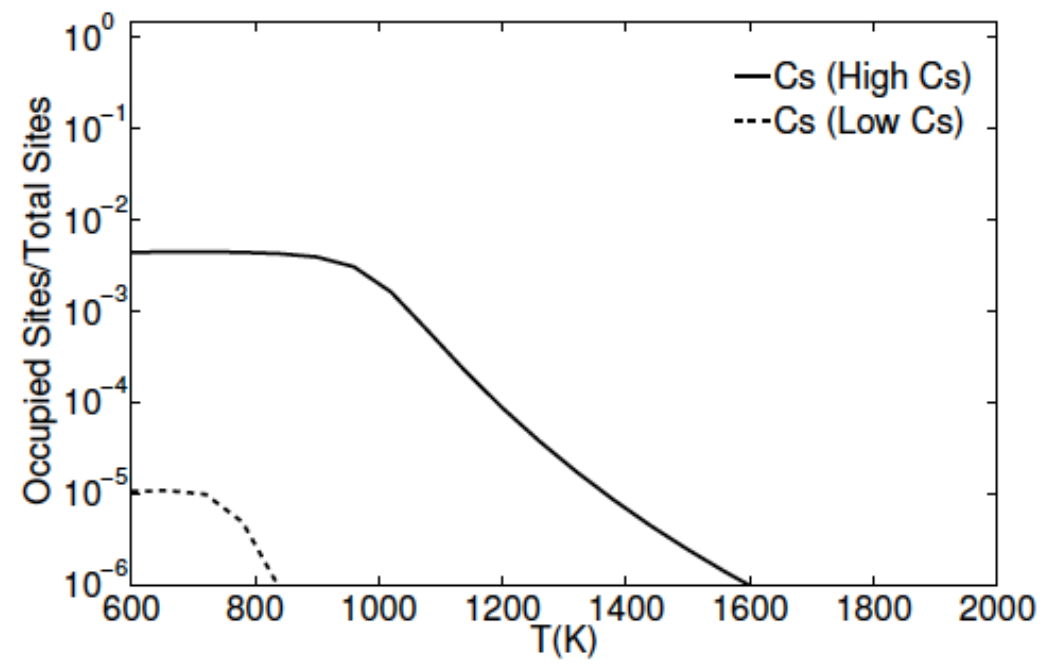

Figure 19. Graphite surface coverage for $\mathrm{P}_{02}=10^{-20}$ atm. Simulation done with exclusively DFT energies.

Figures 20 and 21 present sorption behavior for the different species on the graphite core for $\mathrm{P}_{02}=0.2$ atm. Figure 20 does not have curves for $\mathrm{Cs}_{2} \mathrm{O}$ bound to graphite since weak binding leads to no surface sorption of $\mathrm{Cs}_{2} \mathrm{O}$ in this case. At this high $\mathrm{P}_{02}$, binding to the carbon surface is very limited. Compared with the low pressure regime, it is observed that at this pressure the most stable gas phase for the Cs inventory is the $\mathrm{Cs}_{2} \mathrm{O}$ gas phase, which does not bind to the surface in this temperature range. Comparing Figs. 18 and 21, one can see that at a higher pressure the transition from the Cs to the $\mathrm{Cs}_{2} \mathrm{O}$ gas phase occurs at a higher temperature. As a result, Cs gas inventories decrease and binding to the surface is basically zero for both concentration regimes. The same trend that was observed at low 
pressure occurs here, in that there is a crossover from $\mathrm{Cs}$ to $\mathrm{Cs}_{2} \mathrm{O}$ as the dominant species as temperature is lowered. In general, as $\mathrm{P}_{02}$ is increased there is more $\mathrm{Cs}_{2} \mathrm{O}$ gas, which will not bind to the graphite surface and will limit the amount of Cs in gas phase that would potentially bind to the surface. It is also important to note that there is no $\mathrm{O}_{2}$ binding to the surface both for the high and low pressure regimes. In this temperature range, $\mathrm{P}_{02}$ favors the gas phase since the binding energy to the surface is very small.

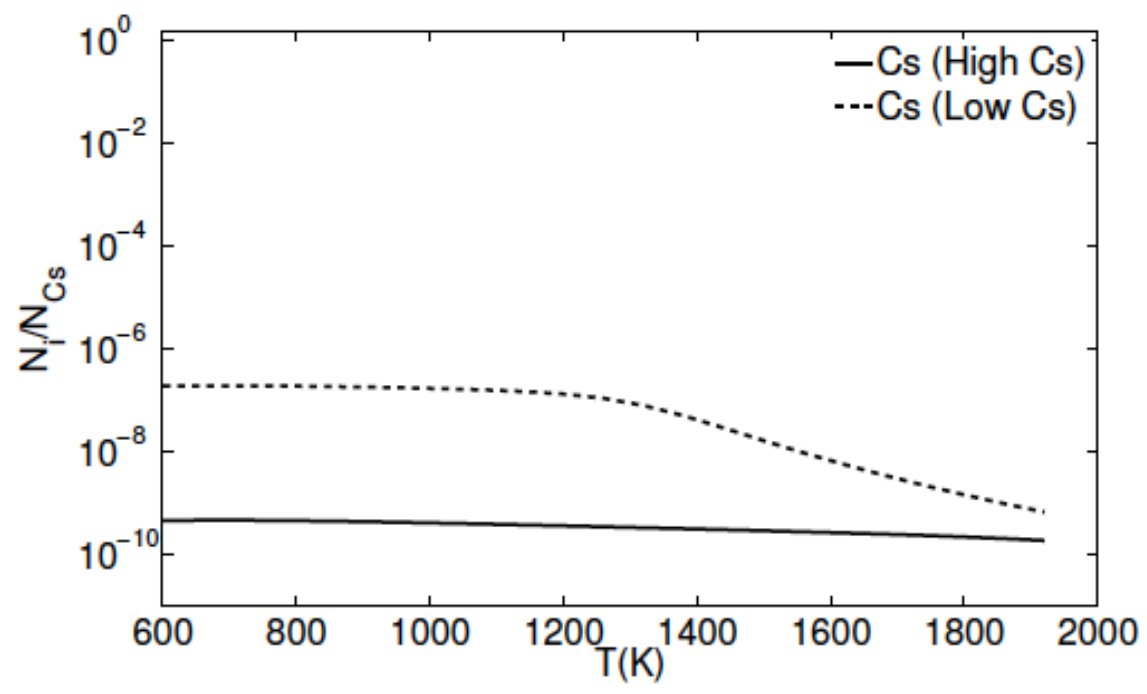

Figure 20. Inventory of species on graphite core for $\mathrm{P}_{02}=0.2$ atm. Simulation done with exclusively DFT energies.

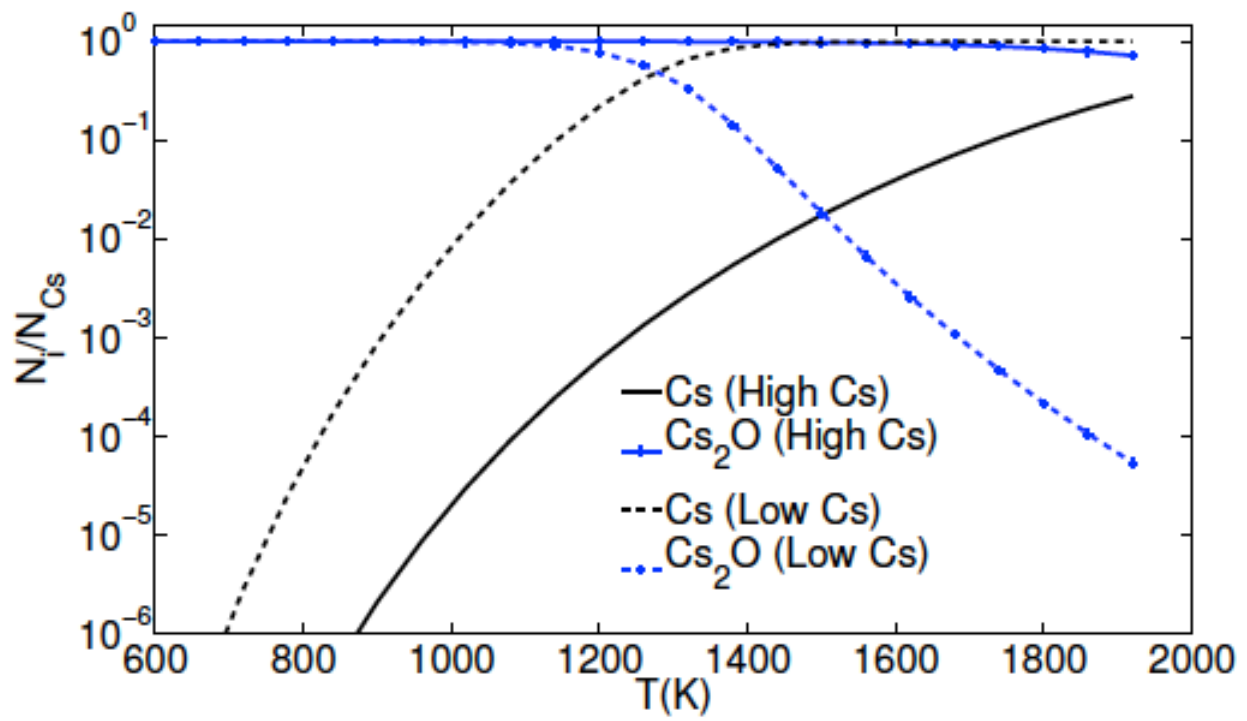

Figure 21. Inventory of species in gas phase for $\mathrm{P}_{02}=0.2$ atm. Simulation done with exclusively DFT energies. 


\section{DFT exclusive model- Amorphous Carbon Core}

Sorption results for the amorphous carbon core were calculated using DFT only binding energies. Figures 22 to 24 present sorption behavior for the different species on the amorphous carbon core for $\mathrm{P}_{02}=10^{-20}$ atm. Figure 23 does not have curves for $\mathrm{Cs}_{2} \mathrm{O}$ bound to graphite since weak binding leads to no surface sorption of $\mathrm{Cs}_{2} \mathrm{O}$ in this case. It is shown in Fig. 22 that for the case of amorphous carbon, both $\mathrm{Cs}$ and $\mathrm{Cs}_{2} \mathrm{O}$ bind to the surface. It can be noticed from Tables 3, 7 and 8 that binding energies for $\mathrm{Cs}_{2} \mathrm{O}$ on the amorphous carbon surface are higher than they were for the case of graphite and that they are also higher than those of Cs by at least $1.7 \mathrm{eV}$ for the case of amorphous carbon. For the low concentration regime, all $\mathrm{Cs}$ is adsorbed by the surface as atomic Cs at a temperature of about $1000 \mathrm{~K}$. In general, the stability of $\mathrm{Cs}_{2} \mathrm{O}$ vs. Cs causes it to become the dominant species by about $800 \mathrm{~K}$. On average, $\mathrm{Cs}_{2} \mathrm{O}$ binds more strongly to the surface than atomic $\mathrm{Cs}$ and, as a result, the Cs inventory that was bound as atomic Cs to the surface at higher temperatures is replaced by $\mathrm{Cs}_{2} \mathrm{O}$ immediately as it becomes available with the decrease of temperature. The overall effect of this change of species on the surface is that at a temperature of around $850 \mathrm{~K}$ there is a decrease of total Cs on the surface. As the temperature is further decreased, the entire $\mathrm{Cs}$ inventory sorbed by the surface is in the form of $\mathrm{Cs}_{2} \mathrm{O}$. For the high concentration regime, it is observed that $\mathrm{Cs}_{2} \mathrm{O}$ dominates surface binding below about $1800 \mathrm{~K}$ and the surface is saturated (i.e., all the surface sites are filled) below about $1200 \mathrm{~K}$. As the temperature decreases, there is a transition from $\mathrm{Cs}$ to $\mathrm{Cs}_{2} \mathrm{O}$ binding similar to that observed for the low concentration regime. However, in this case the total Cs inventory is so high that there is enough $\mathrm{Cs}_{2} \mathrm{O}$ to saturate the surface at any temperature below $1200 \mathrm{~K}$. Furthermore, since the binding energy of $\mathrm{Cs}_{2} \mathrm{O}$ on amorphous carbon is higher than that of atomic Cs, the surface is predominantly covered with $\mathrm{Cs}_{2} \mathrm{O}$ instead of atomic Cs even at temperatures where $\mathrm{Cs}$ is the dominant species in the gas phase (the gas phase does not become primarily $\mathrm{Cs}_{2} \mathrm{O}$ until below about $950 \mathrm{~K}$ ). In other words, the surface species prefer to be $\mathrm{Cs}_{2} \mathrm{O}$ vs. Cs when compared to the gas species due to the strong $\mathrm{Cs}_{2} \mathrm{O}$ vs. Cs surface binding. 


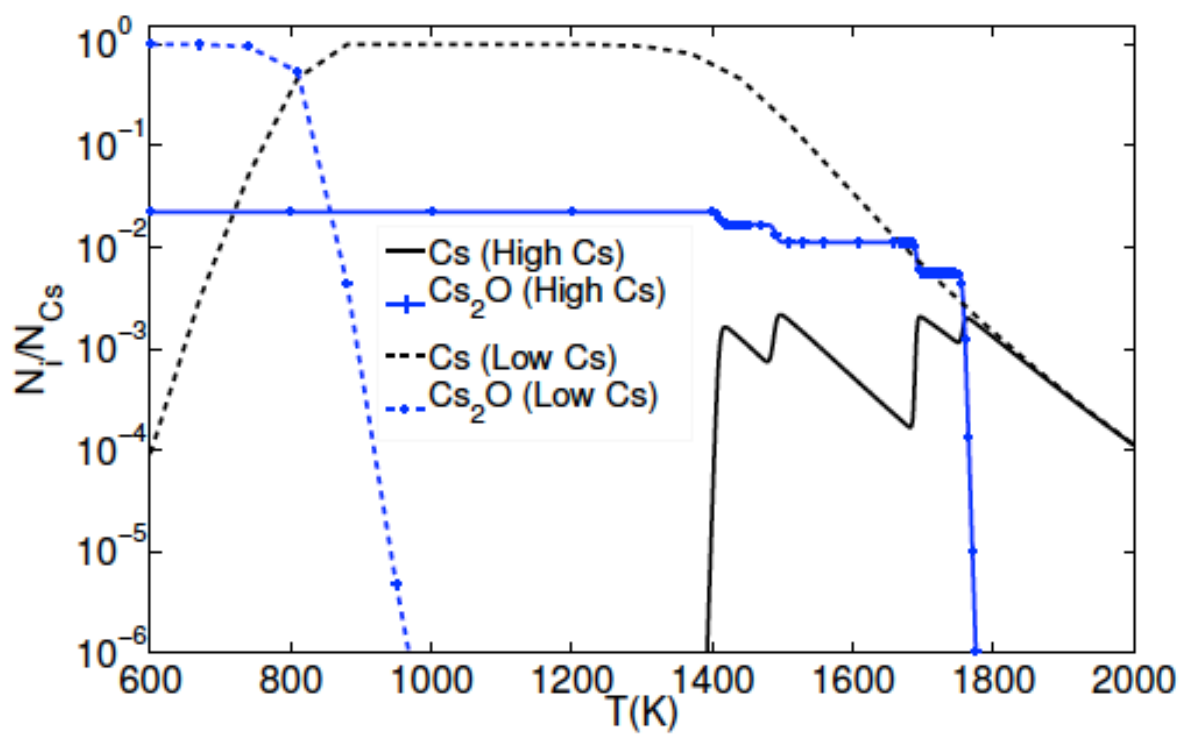

Figure 22. Inventory of species for $\mathrm{P}_{02}=10^{-20} \mathrm{~atm}$ for an amorphous carbon core.

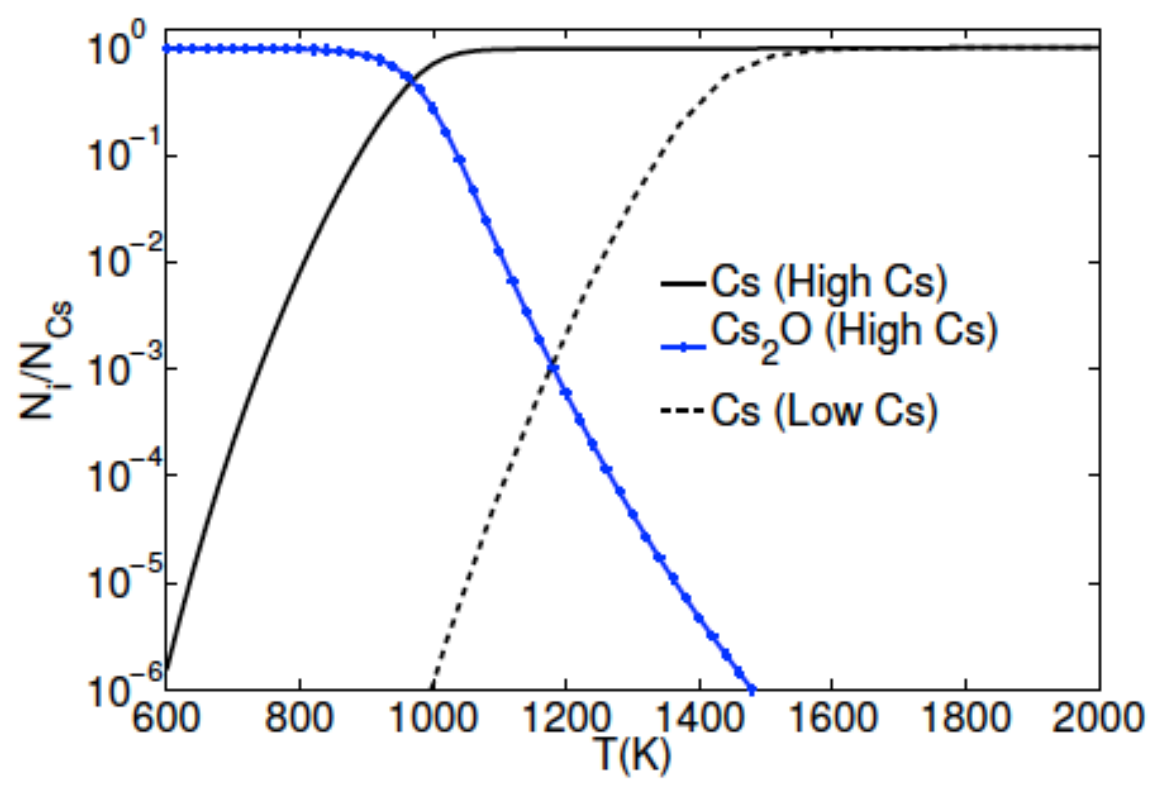

Figure 23. Inventory of species in gas phase for $\mathrm{P}_{02}=10^{-20}$ atm for an amorphous carbon core. 


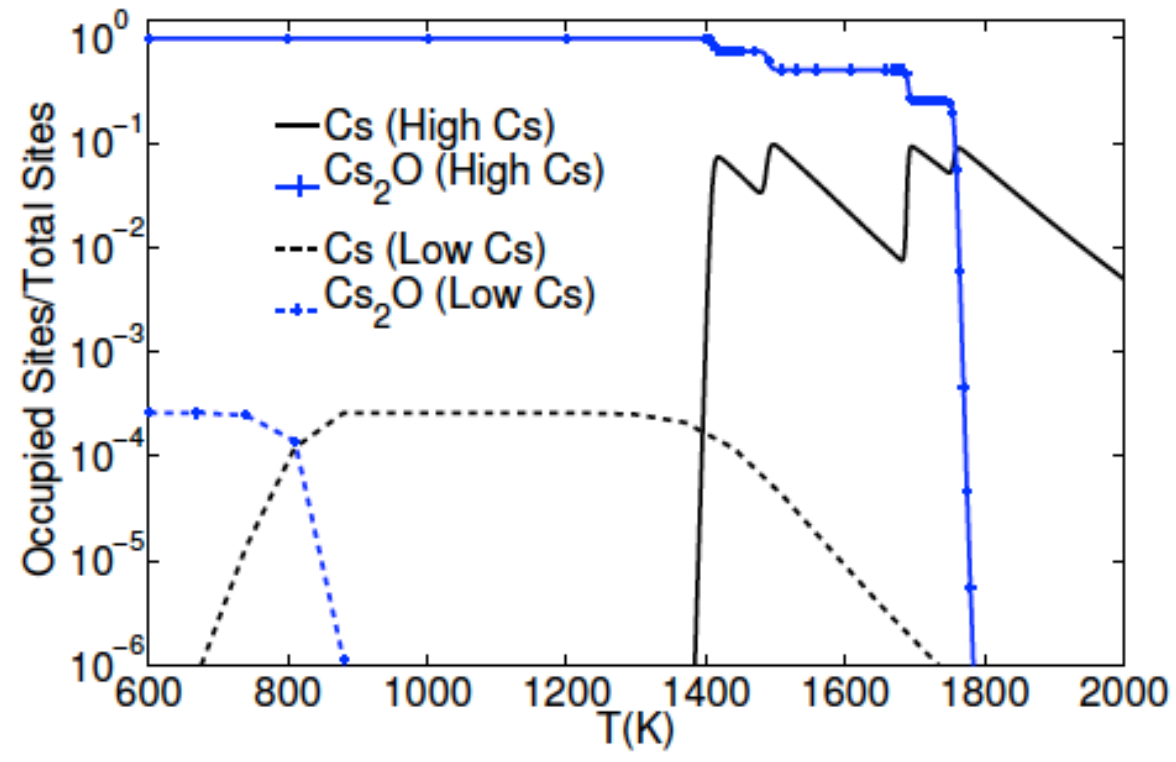

Figure 24. Surface coverage for $\mathrm{P}_{02}=10^{-20}$ atm for an amorphous carbon core.

Figures 25 to 27 present sorption behavior for the different species on the amorphous carbon core for $\mathrm{P}_{02}=0.2 \mathrm{~atm}$. The figure shows that, similar to the low $\mathrm{P}_{02}$ regime, Cs will saturate the carbon surface with the decrease of temperature for the high concentration regime and all Cs will be deposited on the surface for the low concentration regime. Also similar to the low $\mathrm{P}_{02}$ regime, it can be seen from Figure 27 that there is a transition between atomic $\mathrm{Cs}$ binding to $\mathrm{Cs}_{2} \mathrm{O}$ binding to the surface as temperature decreases. When compared to the behavior at lower $\mathrm{P}_{02}$ the transition to $\mathrm{Cs}_{2} \mathrm{O}$ occurs at a higher temperature due to the higher $\mathrm{P}_{02}$. For the high concentration regime, $\mathrm{Cs}_{2} \mathrm{O}$ is the dominant species on the surface. This behavior very similar to the results for the low $\mathrm{P}_{02}$ regime, the difference being that at higher $\mathrm{P}_{02}$, surface saturation and the transition from $\mathrm{Cs}$ to $\mathrm{Cs}_{2} \mathrm{O}$ binding to the surface both take place at higher temperatures. In general, results for sorption on amorphous carbon surfaces suggest that, for the temperature range evaluated in this work, most Cs will be deposited in the surface even at high $\mathrm{P}_{02}$. This is in contrast to the graphite core where even at low $\mathrm{P}_{02}$, Cs sorption was limited. These findings suggest that for small Cs release conditions under $\mathrm{O}_{2}$ ingress, all $\mathrm{Cs}$ will be contained by the amorphous carbon surface. However, for the case of high release conditions, both at high and low $\mathrm{P}_{02}$, the carbon surface in the reactor will saturate and most of the Cs inventory will be in gas phase, increasing the chances of Cs release to the atmosphere. 


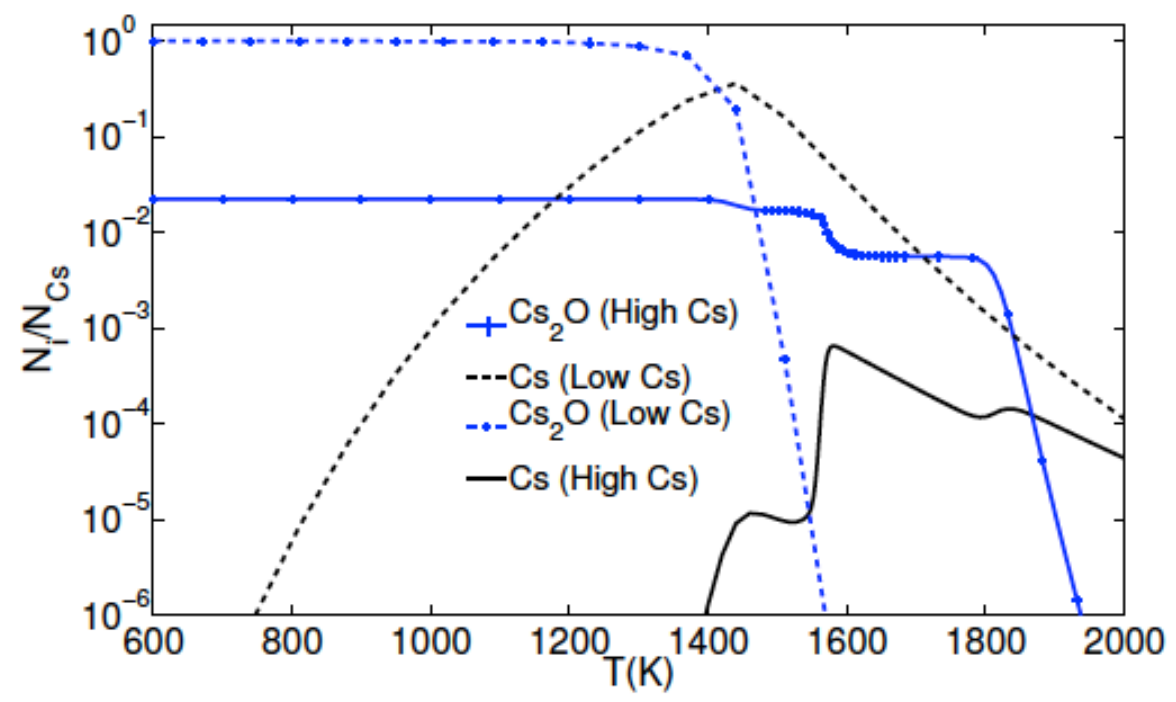

Figure 25. Inventory of species for $\mathrm{P}_{02}=0.2$ atm for an amorphous carbon core.

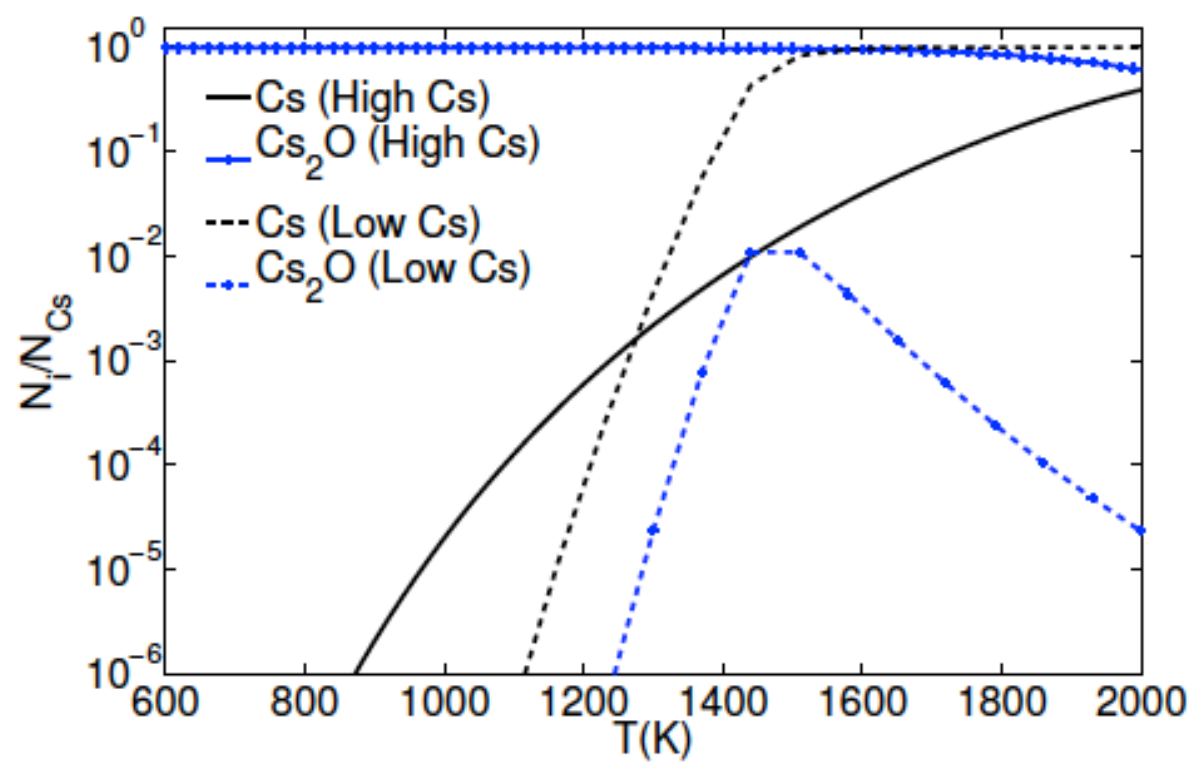

Figure 26. Inventory of species in gas phase for $\mathrm{P}_{02}=0.2$ atm for an amorphous carbon 


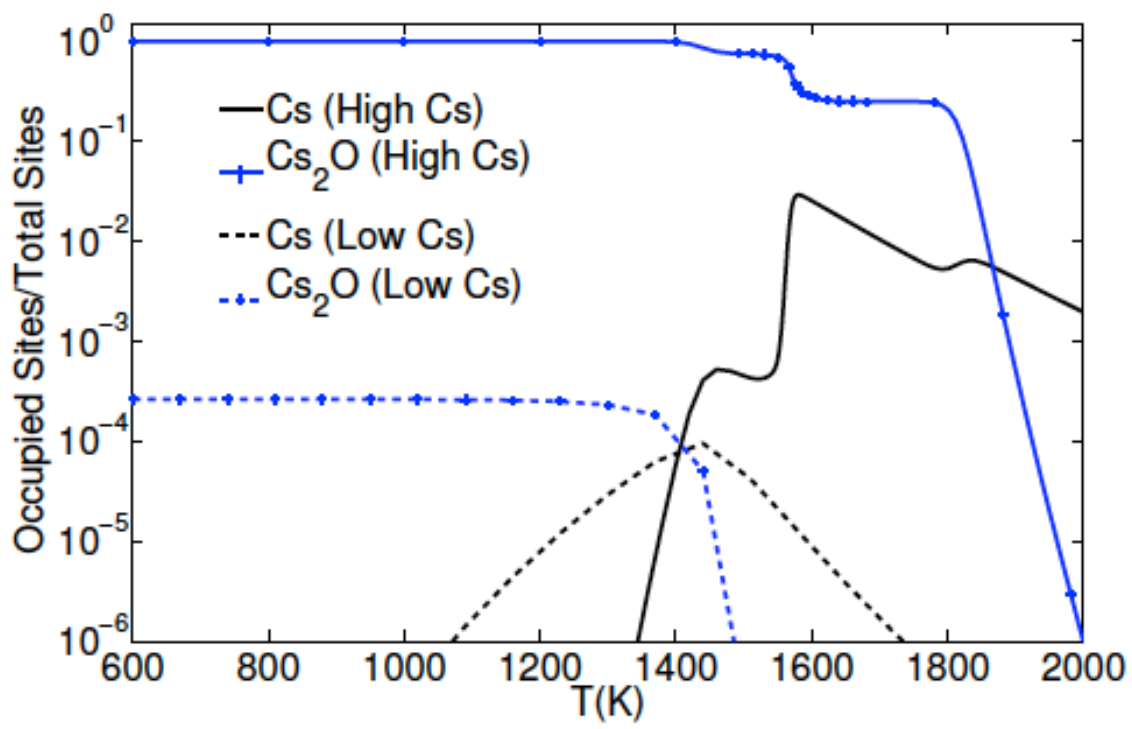

Figure 27. Surface coverage for $\mathrm{P}_{02}=0.2$ atm for an amorphous carbon core.

\section{Combined DFT and experimental model-Graphite Core}

In this section, calculations for the sorption behavior in the reactor's vessel core using a combination of DFT and experimental results are presented. In this case, the binding energy of $\mathrm{Cs}$ is based on experimental values and the binding energies of $\mathrm{Cs}_{2} \mathrm{O}$ and $\mathrm{O}_{2}$ were calculated using DFT. In these calculations we use a constant binding energy $\mathrm{E}_{\mathrm{b}, \mathrm{Cs}}=3.0 \mathrm{eV}$ which is within the range of values presented in Table 3. For the temperature range of interest, a variation of $0.6 \mathrm{eV}$ on the binding energy leads to negligible changes in the sorption behavior that will not have an effect on the qualitative analysis presented in this work. The model in this section is considered to be for a graphite core, and the DFT energies are the graphite binding energetics. However, it should be noted that the experimental binding energies are likely strongly influenced by deviations of the core from perfect graphite and reflect the binding properties of defects. Figures 28 to 30 present sorption behavior for the different species on the graphite core for $\mathrm{P}_{02}=10^{-20}$ atm using the combined sorption model. Curves for $\mathrm{Cs}_{2} \mathrm{O}$ bound to graphite are not included in Fig. 28 since weak binding leads to no surface sorption of $\mathrm{Cs}_{2} \mathrm{O}$ in this case. One can see from Fig. 28 that, for the low concentration regime, there is significant Cs sorption with most of Cs inventory already sorbed by the surface at a temperature below about $1100 \mathrm{~K}$. For the high concentration regime, Fig. 30 shows that all surface sites are saturated at a temperature below about $1300 \mathrm{~K}$. The figure does not have curves for $\mathrm{Cs}_{2} \mathrm{O}$ bound to graphite since weak binding leads to no surface sorption of $\mathrm{Cs}_{2} \mathrm{O}$ in this case. The figure shows that for the high concentration case there is still significant Cs in the gas phase, since the total Cs high fission product release conditions are so high that Cs is able to saturate the surface and also have most of the Cs inventory in gas phase. Figure 29 shows results for the species in the gas phase. The figure does not have a curve for $\mathrm{Cs}_{2} \mathrm{O}$ bound to graphite at low Cs since weak 
binding leads to no surface sorption of $\mathrm{Cs}_{2} \mathrm{O}$ in this case. It is shown in the figure that for both concentration regimes $\mathrm{Cs}_{2} \mathrm{O}$ is only found for the lower temperatures and only in gas phase. This trend is caused by the high value of the experimental binding energy of Cs compared to that of $\mathrm{Cs}_{2} \mathrm{O}$ and the low $\mathrm{P}_{02}$. Comparing these results with the DFT exclusive model, one can see that at low $\mathrm{P}_{02}$ taking the experimental value for the binding energy of Cs, which is higher than the one calculated using DFT, leads to increased Cs sorption for the low concentration regime and to surface saturation for the high concentration regime.

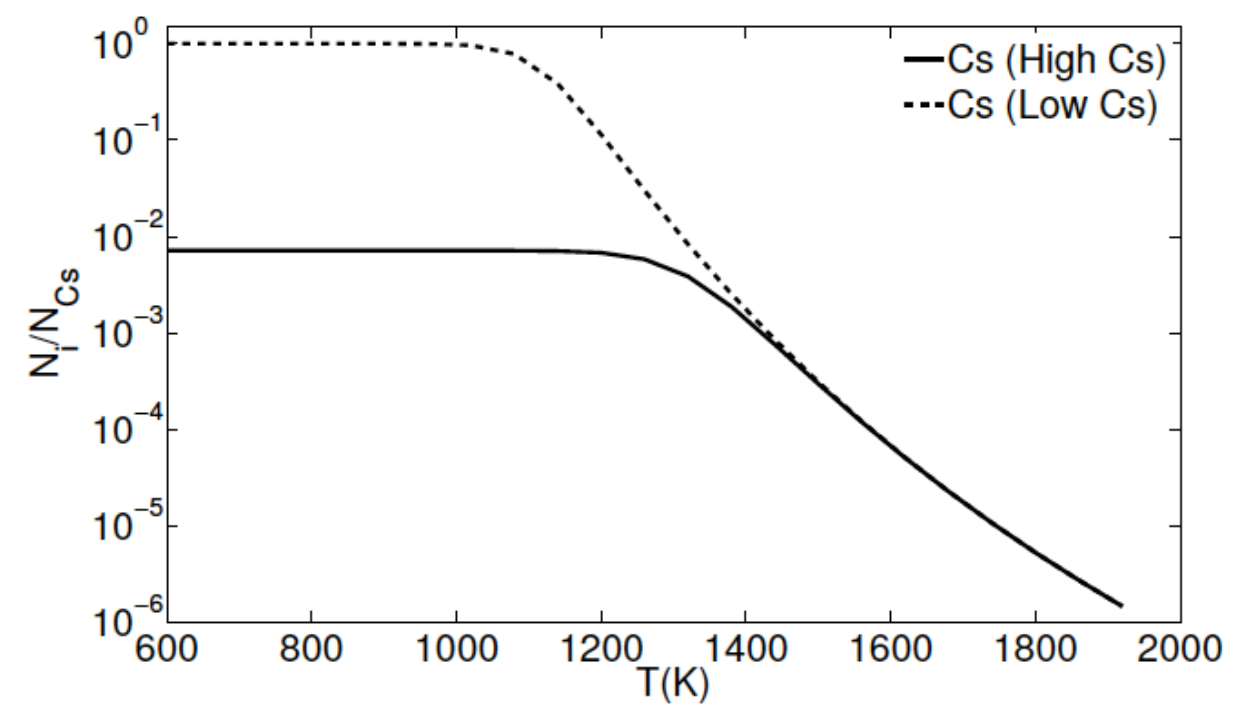

Figure 28. Inventory of species on graphite core for $\mathrm{P}_{02}=10^{-20} \mathrm{~atm}$ using the combined sorption model.

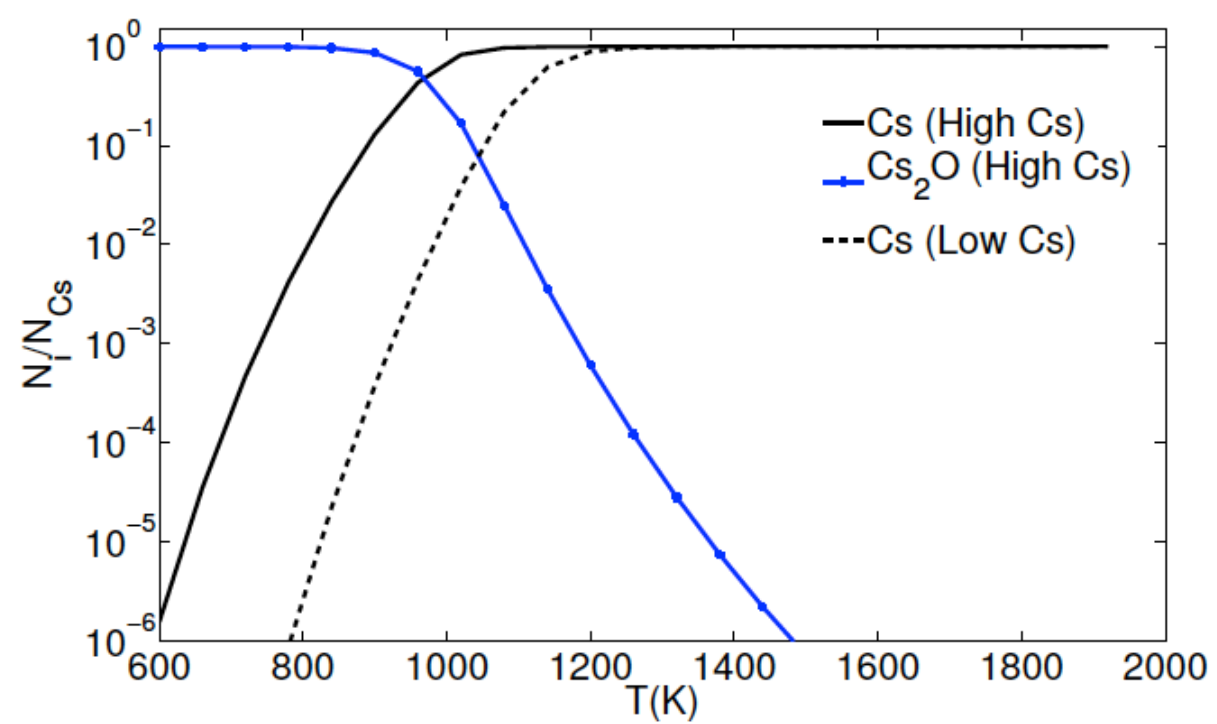

Figure 29. Inventory of species in gas phase $\mathrm{P}_{02}=10^{-20}$ atm using the combined sorption model. 


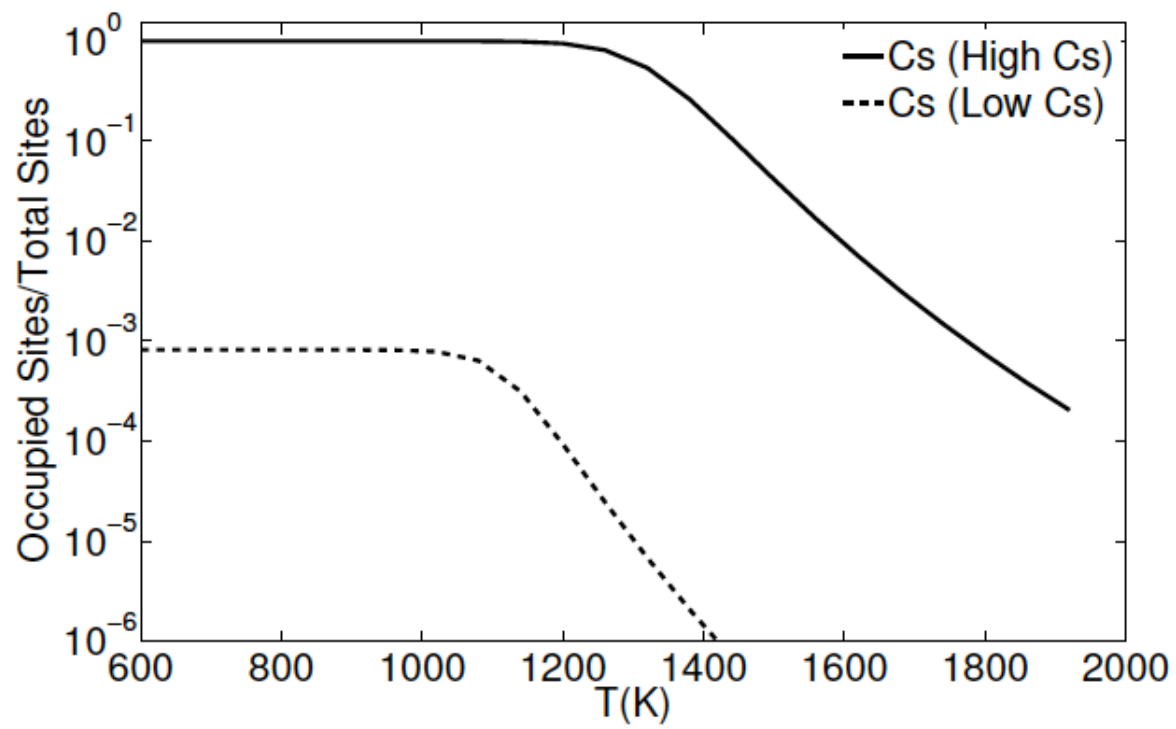

Figure 30. Graphite surface coverage for $\mathrm{P}_{02}=10^{-20}$ atm using the combined sorption model.

Figures 31 to 33 present sorption behavior for the different species on the graphite core for $\mathrm{P}_{02}=0.2$ atm. Curves for bound $\mathrm{Cs}_{2} \mathrm{O}$ are not included in Figs. 31 and 33 since weak binding leads to no surface sorption of $\mathrm{Cs}_{2} \mathrm{O}$ in this case. It is shown in Fig. 30 that similar to the low pressure regime, eventually Cs saturates the surface for the high concentration regime and all Cs is deposited on the surface for the low concentration regime at low enough temperature. However, the higher the $\mathrm{P}_{02}$ the lower the value of this temperature. The reason for this trend of decreasing Cs binding with increasing $\mathrm{P}_{02}=0.2 \mathrm{~atm}$ is that for higher $\mathrm{P}_{02}$ one forms more weakly binding $\mathrm{Cs}_{2} \mathrm{O}$, leading to a decrease on the amount of $\mathrm{Cs}$ available to bind to the surface as atomic Cs.

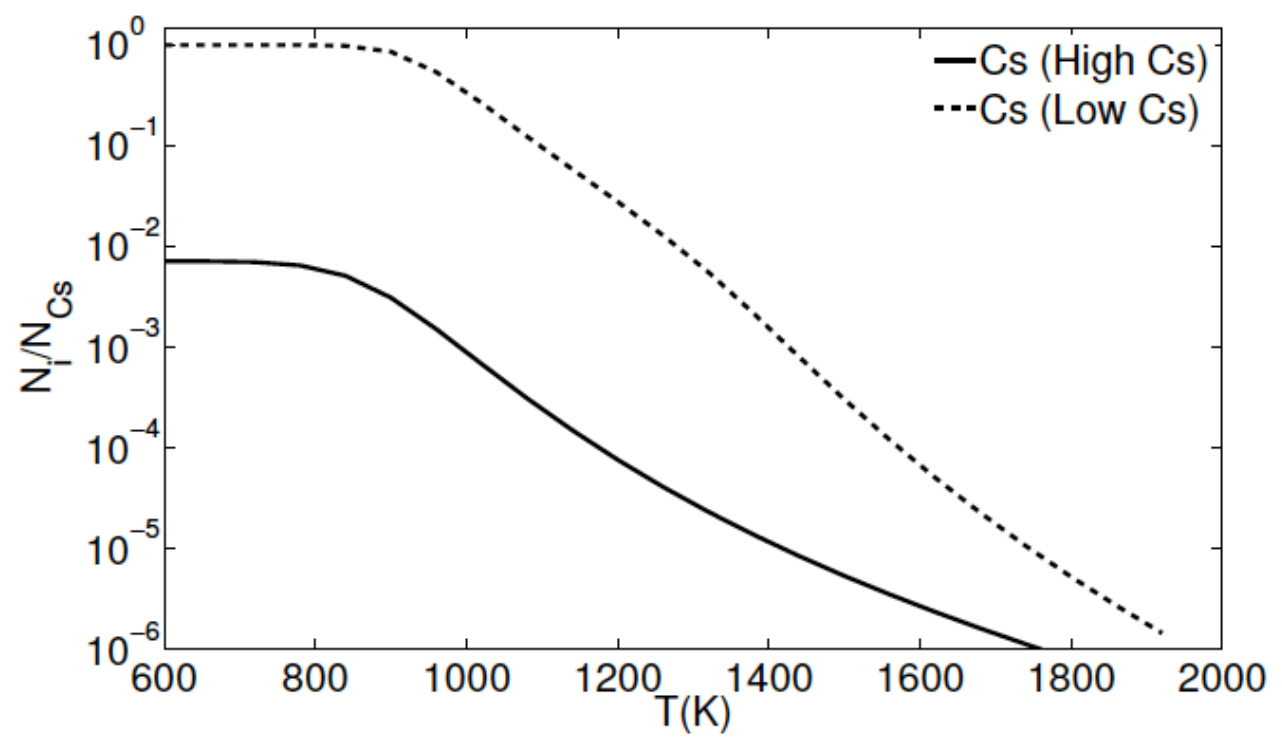


Figure 31. Inventory of species on graphite core for $\mathrm{P}_{02}=0.2$ atm using the combined sorption model.

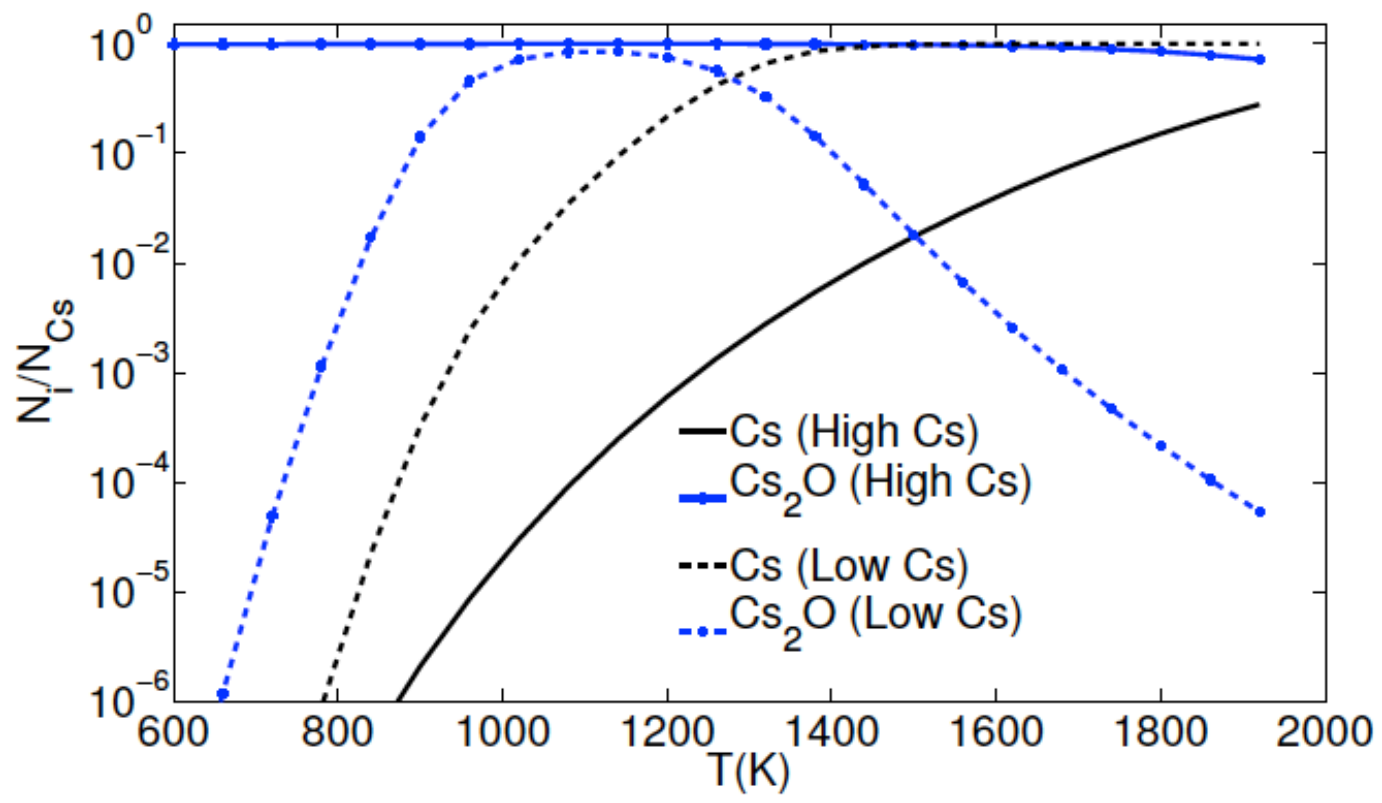

Figure 32. Inventory of species in gas phase for $\mathrm{P}_{02}=0.2 \mathrm{~atm}$ using the combined sorption model.

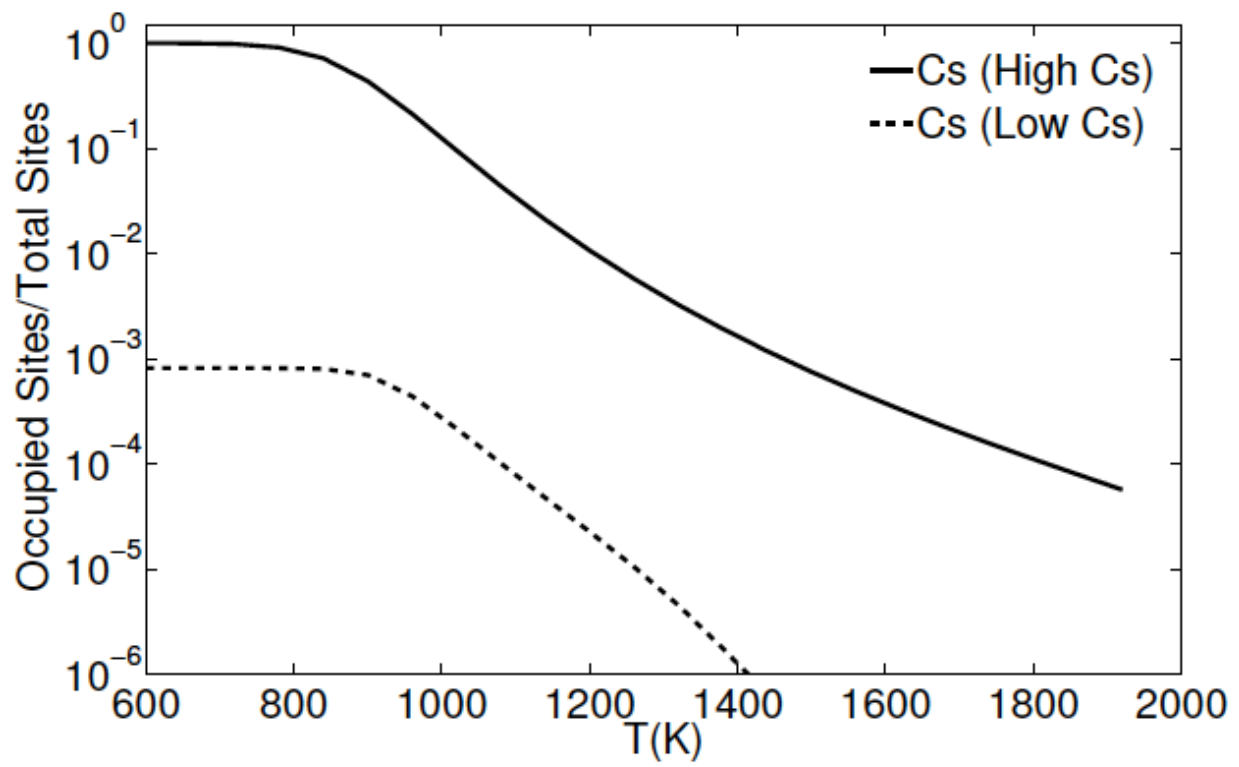

Figure 33. Graphite surface coverage for $\mathrm{P}_{02}=0.2 \mathrm{~atm}$ using the combined sorption model.

\subsection{Discussion and conclusion}

From a general standpoint, it is evidenced by the review performed in this work, significant effort has been made in the characterization and understanding of fission product sorption 
in nuclear materials. The accurate prediction of fission product retention in graphite depends on having an isotherm model that correctly describes fission product sorption. It is also desirable to understand the physics governing sorption, which has been linked to graphite properties such as coke content, impregnation and porosity, and environmental conditions (i.e., irradiation). Future work aimed to characterize current nuclear carbon materials will certainly offer an ideal complement to simulation efforts such as the one performed in this research.

Regarding numerical simulations, the findings presented in this study show that numerical modeling and DFT simulations in particular offer a valuable tool to understand and characterized the behavior of carbon materials in the nuclear reactor. A systematic study combining experiments and simulations similar to those presented here can be used to take this study even further and can lead to a level of characterization of carbon materials that will provide an increased level of confidence when predicting fission product release and sorption.

From a more detailed standpoint, the research activities performed as part of this research project allow to draw the following conclusions:

- Both fission produces $\mathrm{Cs}$ and $\mathrm{Sr}$ are able to bind strongly to some carbon structures, with binding energies from the atomic state reaching values in the 4 to $6 \mathrm{eV}$ range for several carbon surfaces. Binding energies for Cs and Sr change considerably for different carbon structures, with pristine sp2 graphite providing the weakest binding sites while graphite with defects and carbons with significant sp3 bonding (amorphous carbon and diamond) where found to provide much stronger binding energetics. Cs and Sr exhibit similar binding behavior, with the strength of the binding governed by the valence, electronegativity, and atomic stability of each adatom. The stronger binding of defected graphite and sp3 bonded surfaces is consistent with experimentally determined binding energies and with experimental observation linking stronger binding energies to coke rich amorphous carbon structures containing sp3 phases. The calculated results are also in agreement with the interpretation of experimental results on sorption to unirradiated and irradiated graphite, where it has been suggested that neutron irradiation induced vacancies are responsible for stronger sorption.

- For the specific case of nuclear materials, DFT results predict that Cs and $\mathrm{Sr}$ will bind more strongly to fuel rod matrix than to pristine graphite due to the disordered structure and sp3 bonds in the amorphous carbon present in the fuel rod matrix. It is also expected that as nuclear graphite is irradiated, more defects will be created in the graphite structure, leading to stronger Cs and Sr binding.

- An isotherm model developed to predict Cs sorption in HTR reactor components during normal and $\mathrm{O}_{2}$ ingress conditions has been derived. The isotherm model developed in this research study can be expanded to study the sorption of other fission products as well as the competitive binding to the carbon surface. Variations of the model using DFT only and a combination of DFT and experimental binding energies were used to predict fission product sorption in a HTR vessel. For the case of sorption on graphite, the DFT isotherm model predicts lower Cs sorption than experimental studies on nominally graphitic carbon, since DFT calculations assume 
a pristine graphite surface with no defects. Results obtained with the isotherm model using both DFT and experimental energetics predict a higher sorption of Cs on the amorphous carbon surface than on graphite.

- Simulations conducted in this work focused on determining the effect of temperature, $\mathrm{P}_{02}$, Cs inventory and the type of carbon structure have on fission product sorption during $\mathrm{O}_{2}$ ingress conditions. It is important to note that, in an actual reactor the carbon core is composed by both amorphous and graphitic carbon structures. As an approximation, in this research, we studied the two limiting cases: a core made of pristine graphitic carbon and a core made of amorphous carbon. From the calculations presented here, it is possible to extract some conclusions about what to expect in an actual reactor. In order to determine the sorption behavior that can be expected at the core, we focus our attention to the graphitic carbon in the core. This graphitic carbon in is not a pristine graphite structure. Instead, it is expected to have edge defects and vacancies, which will provide the main sites for the fission products to bind. Previous work on the binding behavior of fission products to graphite showed that, although binding energies on nuclear graphite are somewhat lower than those for Fuel Rod Matrix material (a highly amorphous carbon structure), the binding behavior of nuclear graphite is in the same range as that of an amorphous carbon structure. Furthermore, as the operation time of the reactor increases, the presence of defects in graphitic carbon, vacancies in particular, will tend to increase; As more nuclear cycles go by, irradiation will amorphize the graphitic carbon structures of the core, which in turn will lead to increased fission product sorption. Experimental results have shown that the sorption capacity of irradiated graphitic carbon is equal, in some cases higher, than that of amorphous carbon. With this in mind, it can be concluded that results for the amorphous reactor vessel will provide the most realistic results for the sorption behavior under $\mathrm{O}_{2}$ ingress conditions. Results for the case of graphitic carbon may be viewed as a lower limit case that illustrates the hypothetical scenario where the carbon core has a limited fission product sorptivity. These results also underline the central role played by the carbon core under $\mathrm{O}_{2}$ ingress accident conditions. Results obtained for graphitic and an amorphous carbon cores show that the nuclear graphite and Fuel Rod Matrix materials employed in a given reactor can dictate whether or not fission products will be released under some accident conditions.

- Results presented in this study suggest that for the case of $\mathrm{O}_{2}$ ingress accident conditions in the vessel of a HTR, Cs sorption will remain mostly independent of $\mathrm{P}_{02}$. Both at high and low $\mathrm{P}_{02}$, there is significant $\mathrm{Cs}$ sorption by the carbon core. Changes in $\mathrm{P}_{02}$ will determine whether Cs binds as $\mathrm{Cs}$ or as $\mathrm{Cs}_{2} \mathrm{O}$ to the carbon core, with lower $\mathrm{P}_{02}$ favoring $\mathrm{Cs}_{2} \mathrm{O}$ over Cs binding. However, the carbon surface of the core has a limited number of sites where fission products can be adsorbed. This means that for the case of high release conditions, the carbon surface will be saturated and about $98 \%$ of the Cs inventory will be in gas form. This would result in fission product release to the atmosphere in the case of a vessel rupture. It must be noted that this high release conditions are based on older TRISO fuel particles that will no longer be in use in the next generation HTRs. For the case modern TRISO fuel particles, fission product release rates are expected to diminish considerably. Based on the expected 
release rates for modern TRISO fuel particles, results show that for the case of $\mathrm{O}_{2}$ ingress conditions to the reactor vessel, the carbon core surface will be able to sorb most of the Cs inventory for temperatures up to $1200 \mathrm{~K}$. For temperatures of $1800 \mathrm{~K}$ and higher, the Cs inventory will be in gas form and therefore can potentially get released to the atmosphere.

\section{Publications and presentations resulting from the project \\ Publications}

1. "Pore Structure Analysis of Nuclear Graphites IG-110 and NGB-18”, G. Q. Zheng, P. Xu, K. Sridharan and T. R. Allen. Advances in Materials Science for Environmental and Nuclear Technology II, 227, 251, (2010).

2. "A review of fission product sorption in carbon structures", A Londono-Hurtado, I. Szlufarska, R. Bratton and D. Morgan. Journal of Nuclear Materials. 426, pp 245-267, (2012).

3. "First-principles study of Cs and Sr sorption on carbon structures", A Londono-Hurtado, D. Morgan and I. Szlufarska. Journal of Applied Physics, 111, 094912 (2012).

4. DFT-based prediction of fission product sorption on carbon structures under $\mathrm{O}_{2}$ ingress conditions, A. Londono-Hurtado, I. Szlufarska, D. Morgan, J. Nucl. Mater (2013) To be published

\section{Presentations}

5. American Nuclear Society student meeting, Structural and Microstructural Characterization of Nuclear Graphites IG-110 and NBG-18", G. Zheng, P. Xu, K. Sridharan and T. Allen, Ann Arbor, MI, 2010. (POSTER)

6. Materials Research Society Meeting, Fundamental insights into fission product sorption on graphite, A. Londono-Hurtado, D. Morgan, I. Szlufarska, Boston, MA, Fall 2011. (POSTER).

\section{Bibliography}

[1] Triso-Coated Particle Fuel Phenomenon Identification and Ranking Tables (PIRTs) for Fission Product Transport, Due to Manufacturing, Operations, and Accidents, in, U.S. Nuclear Regulatory Comission Report, Report NUREG/CR-6844, Vol. 1.

[2] J. E. G. Fuller, e. al., Microgravimetric Analysis of Corrosion of H-451 Graphite by Collant Impurities: Preliminary Report of Kinetics and Mechanisms, Report ORNL/GCR-90/3, Rev. 0, Oak Ridge National Laboratory, (1992).

[3] H.K. Hinssen, W. Katscher, R. Moormann, Kinetik der Graphit/Sauerstoff-Reaktion im Porendiffusionsonsbereich: Teil II, Graphite V483T, ASR-1RS, ASR-1RG und ATR-2E, Report Jul-2052, Research Center Julich, (1986). 
[4] C. Velasquez, G. Hightower, R.D. Burnette, The Oxidation of H-451 Graphite by Steam, Report GA-A14851, General Atomic Company, (1978).

[5] R. Moormann, Fission Product Transport and Source Terms in HTRs: Experience from AVR Pebble Bed Reactor, Science and Technology of Nuclear Installations, (2008) Article ID 597491.

[6] B.F. Myers, W.E. Bell, Cesium Transport Data for HTGR Systems, in, General Atomic Company, 1979.

[7] K. Verfondern, K. Hilpert, R. Moormann, Sorption of Fission Products on Graphite and its Influence on their Release Behavior in a Pebble Bed HTR Under Accident Contidions, in, KFA Juelich, 1979.

[8] K. Hilpert, H. Gerads, D. Kobertz, Sorption of Strontium by Graphitic Materials, Ber. Bunsenges. Phys. Chem., 89 (1985) 43-48.

[9] D.D. Jensen, M.J. Haire, J.E. Baldassare, D.L. Hanson, Planning Guide for Validation of Fission Product Transport Codes, in, General Atomic, 1975.

[10] C.E. Apperson, SUVIUS: A Circulating and Plateout Activity Program for Gas-Cooled Reactors with Arbitrary Radioactive Chains, in, Los Alamos Scientific Laboratory, 1978.

[11] B.F. Myers, R.E. Morrissey, The Measurement and Modelling of Time-Dependent Fission Product Release from Failed HTGR Fuel Particles Under Accident Conditions, in, General Atomic Company, 1980.

[12] D. Alberstein, C.E. Apperson, D.L. Hanson, B.F. Myers, W.W. Pfeiffer, HTGR Accident Initiation and Progression Analysis Status Report General Atomic. Volume V. AIPA Fission Product Source Terms, General Atomic, GA-A13617 (1976).

[13] R.D. Burnette, Radiochemical Analysis of the First Plateout Probe From the Fort St. Vrain High-Temperature Gas-Cooled Reactor, in, General Atomic Company, 1982.

[14] D.L. Hanson, Results of the General Atomic Deposition Loop Program, in, General Atomic, 1976.

[15] B.F. Myers, W.E. Bell, Strontium Transport Data for HTGR Systems, in, General Atomic Company, 1974.

[16] J.H. Norman, L.R. Zumwalt, H.G. Staley, Thermodynamics of Adsorption of Mixed Metallic Elements on Graphite at High Temperature, in, 1967.

[17] D.L. Hanson, A Review of Fission Product Plateout Investigations at General Atomic, in, General Atomic Company, 1977.

[18] Hudritsch, W. W., PADLOC, a One-Dimensional Computer Program for Calculating Coolant and Plateout Fission-Product Concentrations Part II, in, General Atomic Company, 1981.

[19] GA, Public Service Company of Colorado 330-MW(E) High-Temperature Gas-Cooled Reactor Research and Development Program, in, General Atomic, 1966.

[20] M.J. Haire, L.R. Zumwalt, Cesium Diffusion Coefficients and Other Results from the Analysis of Peach Bottom D13-05 fuel element activity profiles, in, Gulf General Atomic, 1973.

[21] C.E. Milstead, Riedinger, A. B., Zumwalt, L. R., Cesium-graphite sorption isotherms determined by a static method, Carbon, 4 (1966) 99-106.

[22] G. GA, HTGR Base Program Quarterly Progress Report for the Period Ending August 31, 1973, in, 1973.

[23] G. GA, HTGR Base Program Quarterly Progress Report for the Period Ending May 31, 1971, in, 1971.

[24] G. GA, HTGR Base Program Quarterly Progress Report for the Period Ending November 30,1970 , in, 1970.

[25] D. Alberstein, P.D. Smith, M.J. Haire, Metallic Fission Product Release from the HTGR Core, in, General Atomics, 1975. 
[26] R.C. Martin, Compilation of Fuel Performance and Fission Product Transport Models and Database for MHTGR Design, in, Oak Ridge National Laboratory, 1993.

[27] G. Kresse, in, Technische Universitaet Wien, 1993.

[28] G. Kresse, J. Hafner, Phys. Rev. B

, 47

(1993).

[29] D.M. Ceperley, B.J. Alder, Ground-State of the Electron-Gas by a Stochastic Method, Physical Review Letters, 45 (1980) 566-569.

[30] Y.F. Mo, K.T. Turner, I. Szlufarska, Friction laws at the nanoscale, Nature, 457 (2009)

1116-1119.

[31] Y.F. Mo, I. Szlufarska, Roughness picture of friction in dry nanoscale contacts, Physical Review B, 81 (2010) -.

[32] D.W. Brenner, O.A. Shenderova, J.A. Harrison, S.J. Stuart, B. Ni, S.B. Sinnott, A secondgeneration reactive empirical bond order (REBO) potential energy expression for hydrocarbons, Journal of Physics-Condensed Matter, 14 (2002) 783-802.

[33] A. Savin, R. Nesper, S. Wengert, T.F. Fassler, ELF: The electron localization function, Angewandte Chemie-International Edition in English, 36 (1997) 1809-1832.

[34] G. Henkelman, A. Arnaldsson, H. Jonsson, A fast and robust algorithm for Bader decomposition of charge density, Computational Materials Science, 36 (2006) 354-360.

[35] K. Rytkonen, J. Akola, M. Manninen, Density functional study of alkali-metal atoms and monolayers on graphite (0001), PHYSICAL REVIEW B, 75 (2007) -.

[36] K.T. Chan, J.B. Neaton, M.L. Cohen, First-principles study of metal adatom adsorption on graphene, PHYSICAL REVIEW B, 77 (2008) -.

[37] C.E. Apperson, Fission Product Release into the Primary Coolant, in, Los Alamos Scientific Laboratory, 1977.

[38] HTGR Fuels and Core Development Program. Quarterly Report for the Period Ending February 28, 1977, in, General Atomic, 1977.

[39] M.J. Haire, Evaluation of Strontium-90 Radial Concentration Profiles in Peach Bottom HTGR Core 2 Fuel Elements, in, Oak Ridge National Laboratory, 1979.

[40] D.C. Fee, I. Johnson, S.A. Davis, W.A. Shinn, G.E. Staahl, C.E. Johnson, The Cs-U-O phase diagram and its aplication to uraniun-plutinium oxide fst reactro fuel pins, in, Argonne National Laboratory, Argone, Illinois, 1977.

[41] F.A.C.a.F.a.G.W.a.M.B.a.R.N. Grimes, Advanced Inorganic Chemistry, Wiley-Interscience, 1988.

[42] J.L.a.O. Collins, M. F. and Lorenz, R. A., Behavior of Cs, I, and Te in the fission product release program at ORNL, in, Oak Ridge National Laboratory, 1984.

[43] H.B. Callen, Thermodynamics and an introduction to thermostatistics, 2nd ed., Wiley, New York, 1985.

[44] D.S. Sholl, J.A. Steckel, Density functional theory : a practical introduction, Wiley, Hoboken, N.J., 2009.

[45] A. Londono-Hurtado, D. Morgan, I. Szlufarska, First-principles study of Cs and Sr sorption on carbon structures, Journal of Applied Physics, 111 (2012).

[46] NGNP Fuel Qualification White Paper, in, Idaho National Laboratory, 2010.

[47] HTGR-86-024, Preliminary Safety Information Document for the Standard MHTGR, in, Department of Energy, 1986.

[48] T.B. Lindemer, H.G. de Nordwall, An Analysis of Chemical Failure of Coated UO2 and other Oxide Fuels in the High Temperature Gas-Cooled Reactor, in, Oak Ridge National Laboratory, 1974. 
[49] M. Barrachin, R. Dubourg, M. Kissane, V. Ozrin, Progress in understanding fissionproduct behaviour in coated uranium-dioxide fuel particles, JOURNAL OF NUCLEAR MATERIALS, 385 (2009) 372-386. 